\title{
A Review on Effect of Amylose/Amylopectin, Lipid and Relative Humidity on Starch Based Biodegradable Films
}

\author{
Neha J. Hirpara* and M. N. Dabhi \\ Department of Processing and Food Engineering, Junagadh Agricultural University, \\ Junagadh, Gujarat 362001, India \\ *Corresponding author
}

\section{A B S T R A C T}

\section{Keywords}

Biodegradable plastic, Natural polymer, Synthetic polymer, Starch, amylose content, amylopectin content

Article Info

Accepted:

18 March 2021

Available Online:

10 April 2021
Plastic is an unavoidable packaging, handling and coating material for food, medical and agricultural industries as well as agricultural farm. This plastic are made from synthetic polymers. These polymers are objectionable for environment. There is direct need to have option of these synthetic polymers. Many researches on natural polymers were carried out. These natural polymers may be protein, starch, polysaccharides etc. This paper reviewed for starch as natural polymer, chemical form of starch for conversion in plastic film, effect of amylose/amylopectin content, effect of lipid content and effect of relative humidity on properties of starch film. For strengthening of plastic film from starch, a blend with synthetic polymer is also discussed with limited synthetic polymers like polyethylene, polyester, polypropylene, and polylactic acid considering the length of review article.

\section{Introduction}

Packaging industry have high importance of synthetic polymers for packing material manufacturing. After consumption of plastic from synthetic polymers, its waste is objectionable for environment. Generally for environmental maintaining, synthetic polymer based plastics are being substituted by natural polymers. Development of plastic from natural polymers for many uses has been a burning topic for several years due to ever increasing cost of petrochemical materials and environmental alarms. Use of synthetic polymer for general use degrades the environment. It is better to have degradable polymer than degrading environment. Ten years back, natural polymer starch has been assessed in its film making ability for applications in the food packaging area.. It is wrong perception that all the synthetic polymers are non-degradable. Some of the 
synthetic polymers are biodegradable. Hence, advantaging its property with property of starch, starch-based completely biodegradable polymers have potential for uses in biomedical and environmental fields. For increasing the storage life of foods through preservation and protection from microorganism spoilage the packaging is important. The use of this packaging material could be made from natural polymers which are biodegradable to reduce the environment degradation.

Plastics from natural polymers are biodegradable plastics. Biodegradable plastics will be decomposed due to bacteria, fungi or other micro-organisms that use them as food. Synthetic polymers like polyethylene can be biodegradable for the chains having molecular weight of less than 500. Another synthetic polymer polyester is also prone to biodegradation which is rarely used for packaging.

New biodegradable biopolymers are developed using biotechnological processes. This biopolymers are termed as "green plastic", which are derived from plants. This green plastic is the topic of the interest for contemporary scientists as it is ancillary of traditional chemical based plastics. The green plastic should be derived from renewable sources; it should be biodegradable in nature and eco-friendly (Stevens, 2003). Biodegradable plastics are those that can be completely degraded in landfills, composters or sewage treatment plants by the action of naturally occurring micro-organisms. Biodegradability of plastics can be described as the breakdown of plastic monomers or polymers due to biological processes. This biodegradable material can be transformed to biomass, carbon dioxide and water through chemical process that predominantly depend on the surrounding environmental conditions. If it is anaerobic transformation then, methane may be produced. Actually biodegradable plastics leave no toxic, visible or distinguishable residues following degradation (Mooney 2009).

Starch is an interested natural polymers (Teramoto et al., 2003). Due to its complete biodegradability (Araujo et al., 2004), low cost and renewability (Zhang and Shun, 2004), starch is considered as an encouraging aspirant for evolving justifiable resources. In view of this, starch has been receiving growing attention since 1970s (Griffin, 1994; Pareta and Edirisinghe, 2006). A lot of efforts have been exerted to develop starch-based natural polymers for preserving the petrochemical assets, dropping ecological influence and searching more uses (Park et al., 2004; Schwach and Averous, 2004; Stepto, 2006). In this paper, chemical structure of starch, its properties, improvement of properties for plastic film, blending of synthetic polymers and applications of starch-based completely biodegradable (SCBP) polymers is reviewed and presented.

\section{Microstructure of starch}

Starch is a storage polysaccharide in plants. It is initially formed in the amyloplast. The storage site of starch varies from plant to plant. It may be in the seed (cereal grains), in the root and tuber (tapioca and potato), in the stem-pith (sago), and in the fruit (banana). Potato starch granules are large, oval in shape, 15-100 $\mu \mathrm{m}$ in diameter, with pronounced oyster-she11-1ike striations. Corn starch granules are medium sized, round or polygonal in shape, and $15 \mu \mathrm{m}$ in diameter. Rice starch granules are small, polygonal, and 3-8 $\mu \mathrm{m}$ in diameter (Chen, 1990).

Starch is one of the most promising natural polymers because of its inherent biodegradability, overwhelming abundance 
and annual renewability. Starch offers a very attractive low cost and ability to be processed with conventional plastic processing equipment (Jimnez et al., 2012; Arvanitoyannis et al., 1998; Arvanitoyannis, 1999; Yu and Christie, 2005; Yu et al., 2006)

It is well known that synthetic polymer is manmade hence, microstructures can be designed, and molecular weight and molecular weight distribution can be controlled (Jiang et al., 2019). A substantial volume of literature has been published on the properties of starches from various sources (Schwartz and Whistler, 2009; Whistler, et al., 1984). Starch is the chief carbohydrate for energy storage in plants and one of the most abundant plant polymers (Whistler, 1984). Plant starches synthesized in amyloplasts are formed into cold water-insoluble granules that range from few micrometres to more than 100 $\mu \mathrm{m}$ depending on the plant source (French, 1984; Tyson and Ap Rees, 1988).

Starch is an identified hydrocolloid natural polymer and is produced by agricultural plants in the form of granules of different sizes within the endosperm, which are hydrophilic. Starch granules can differ in shape, size, structure, and chemical composition, depending on the source of the starch (Smith 2001). From review of chemical, starch is a carbohydrate polymer having anhydroglucose units linked together mainly through $\alpha$-d- $(1,4)$ glucosidic bonds (Liu, et al., 2009). Earlier studies have reported that starch is a heterogeneous material containing two kinds of microstructures: linear and branched. A linear molecule with a few branches is amylose, whereas a highly branched molecule is amylopectin. Therefore, amylose content contributes to film strength and branched structure of amylopectin generally leads to film with low mechanical properties (Mali et al., 2002). The ratio of amylose/amylopectin depends on the source and age of the starch. Starch generally contains 20 to $25 \%$ amylose and 75 to $80 \%$ amylopectin. For instance, wheat, corn, and potato starch contain 20-30 $\%$ amylose, while its content in waxy starches is lower than $5 \%$ and in high-amylose starches is as high as 50-80 \% (Brown and Poon, 2005).

Linear structure is amylose with $\alpha-1,4$ linked glucose units, and branched structure is amylopectin with highly branched structure of short $\alpha-1,4$ chains linked by $\alpha-1,6$ bonds. Amylose and amylopectin are inherently incompatible molecules; in which amylose having lower molecular weight with a relatively extended shape whereas amylopectin has huge but compact molecules. The presence of amylose tends to reduce the crystallinity of the amylopectin and influence the ease of water penetration into the granules. $\alpha-1,4$ linked glucose are capable of relatively free rotation around $(\phi)$ phi and $(\psi)$ psi torsions, hydrogen bonding between the $\mathrm{O}_{3}$ and $\mathrm{O}_{2}$ oxygen atoms of sequential residues tends to encourage a helical conformation. This helical structures are relatively stiff and may present contiguous hydrophobic surfaces.

The hydrophilic characteristic of starch is useful for improvement of the degradation rate of some degradable hydrophobic polymers. Starch is totally biodegradable in a wide variety of environments. Starch is hydrolyzed into glucose by microorganism or enzymes, which further metabolized into carbon dioxide and water (Primarini and Ohta 2000) (Fig. 1). 
Fig.1
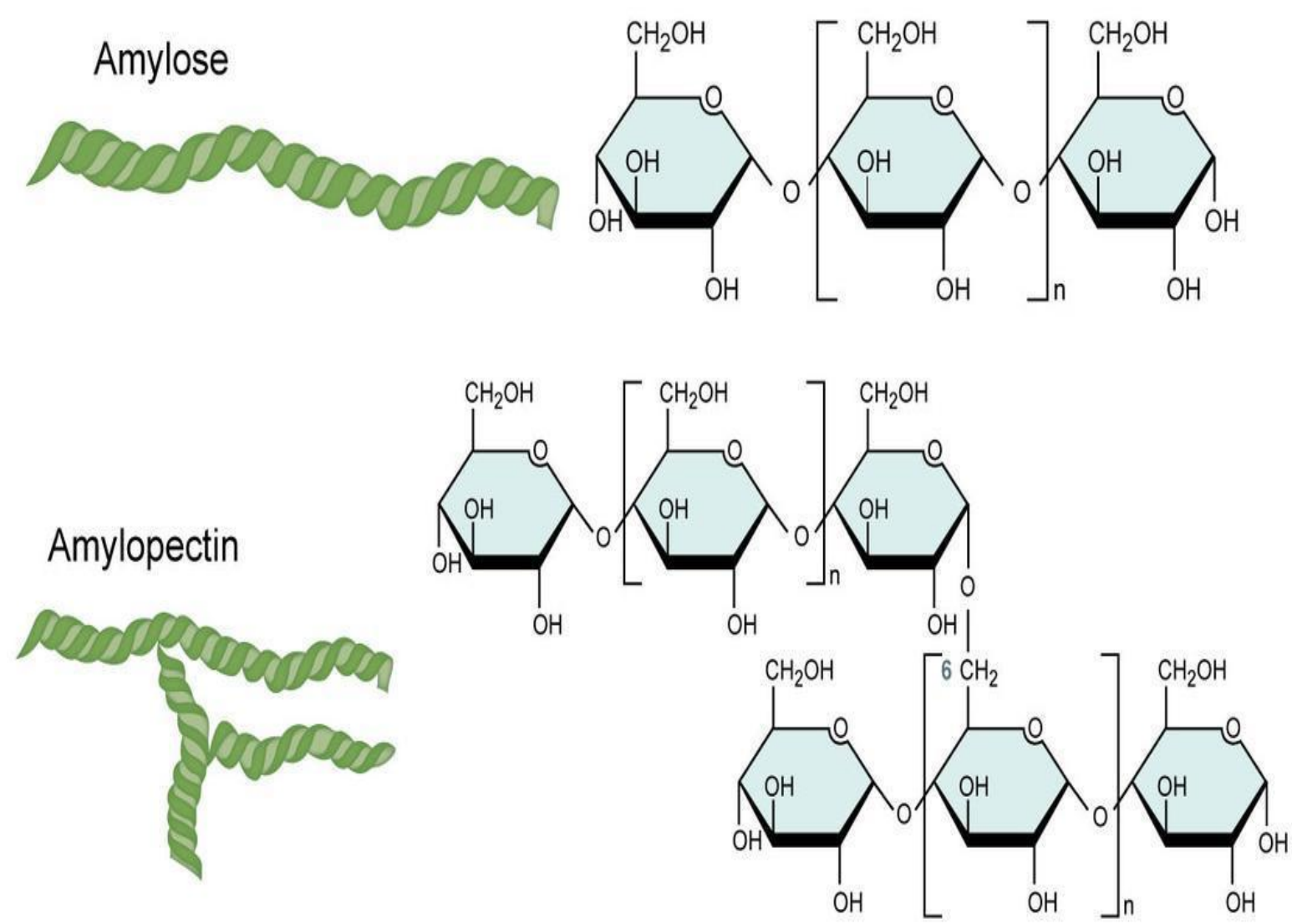

\section{Gelatinization and retrogradation of starch}

Many starch modification processes involve the granular disruption of starch known as gelatinization, mainly to access the $\mathrm{OH}$ functional groups. Gelatinization, in general, is an irreversible order disruption of the granular structure of starch molecule (Koganti et al., 2011). This occurs when starch is heated between 60 and $70{ }^{\circ} \mathrm{C}$ in excess water (Gandini et al., 2016), leading to maximum granular swelling and bursting of the granule. It occurs in two stages; firstly, amyloseamylopectin separation resulting from the absorption of water and swelling of the granule leading to a loss in semi-crystallinity (Domingos et al., 2017) of starch. This separation occurs when the intermolecular hydrogen bonds are broken to loosen the double helices (Wang et al., 2015). It usually begins in the amorphous region because of the ease of water percolation that results in the weakening of the hydrogen bonds. Second, separation and loss of amylose leaching from granule into the solution. The amount of water affects gelatinization; in a low waterstarch ratio, granular swelling is incomplete, leading to a partial loss of crystallinity called melting (Baks et al., 2008). Additionally, the ratio of amylose and amylopectin of the starch granule affects the gelatinization temperature and the quality of the paste. For instance, high amylose starch with amylose to amylopectin ratio of 70:30 gelatinizes at $160-170{ }^{\circ} \mathrm{C}$ (Fang et al., 2004). 


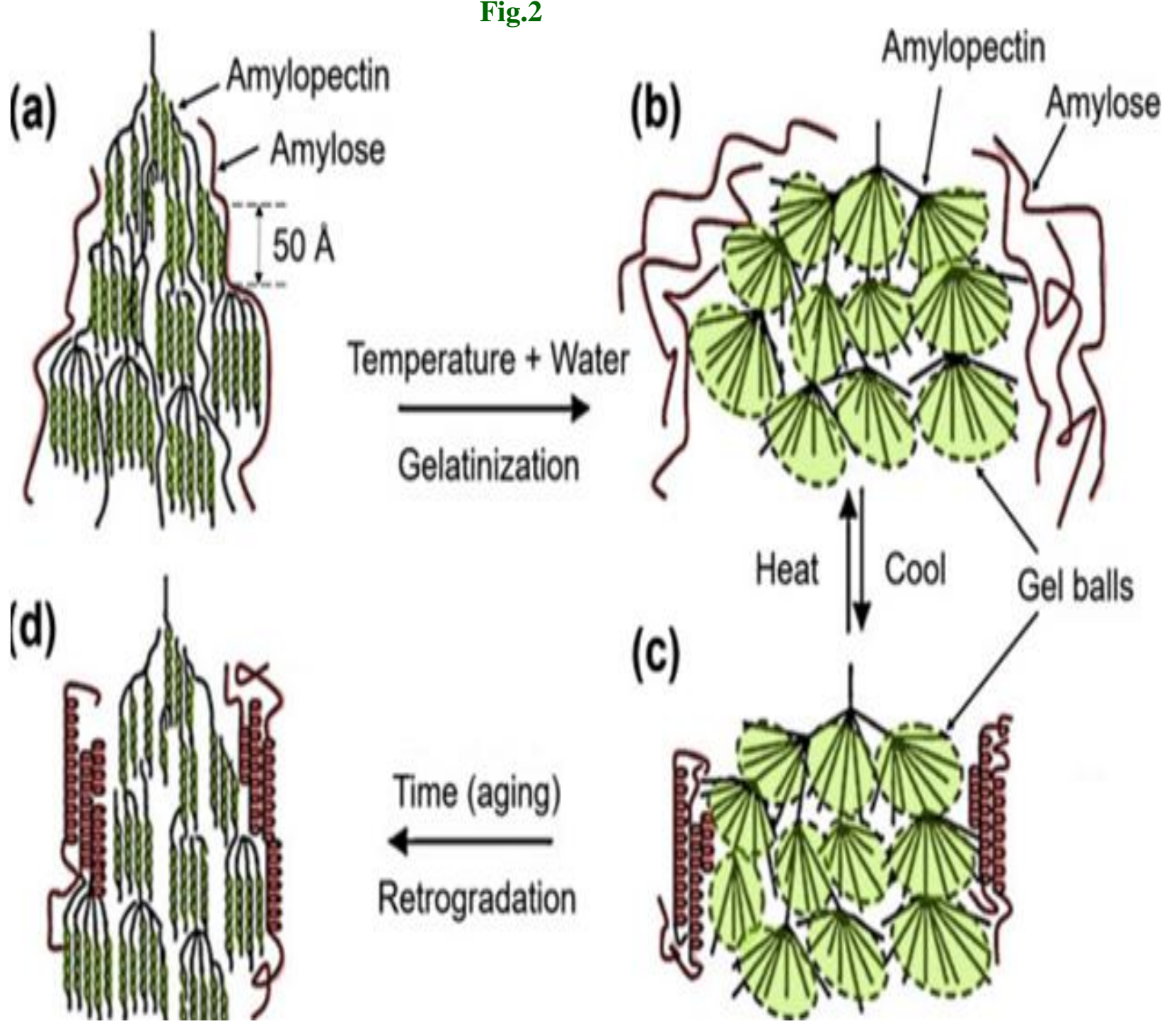

Processes that occur during gelatinization and retrogradation. (a) undisrupted starch granule; (b) absorption of water, swelling of granule, molecular segregation and loss of amylose to solution; (c) realignment of amylose molecules due to cooling (d) recrystallization of amylopectin molecules during storage. Adapted and modified from Liu et al., (2009).

Another method to achieve the gelatinization of starch is through the application of high pressures. While separation of amyloseamylopectin molecules also occurs with high pressure, granule swelling is minimized and solution leaching of amylose is reduced. Like thermal gelatinization, the amount of water and treatment time affects high-pressure gelatinization (Baks et al., 2008). A study by Baks et al., (2008) revealed that at a constant temperature in different starch samples, gelatinization was faster at higher pressures (above $400 \mathrm{MPa}$ ). As gelatinization and granular disordering occur, starch granules lose birefringence, which is a characteristic of gelatinized starch. 
Fig.3
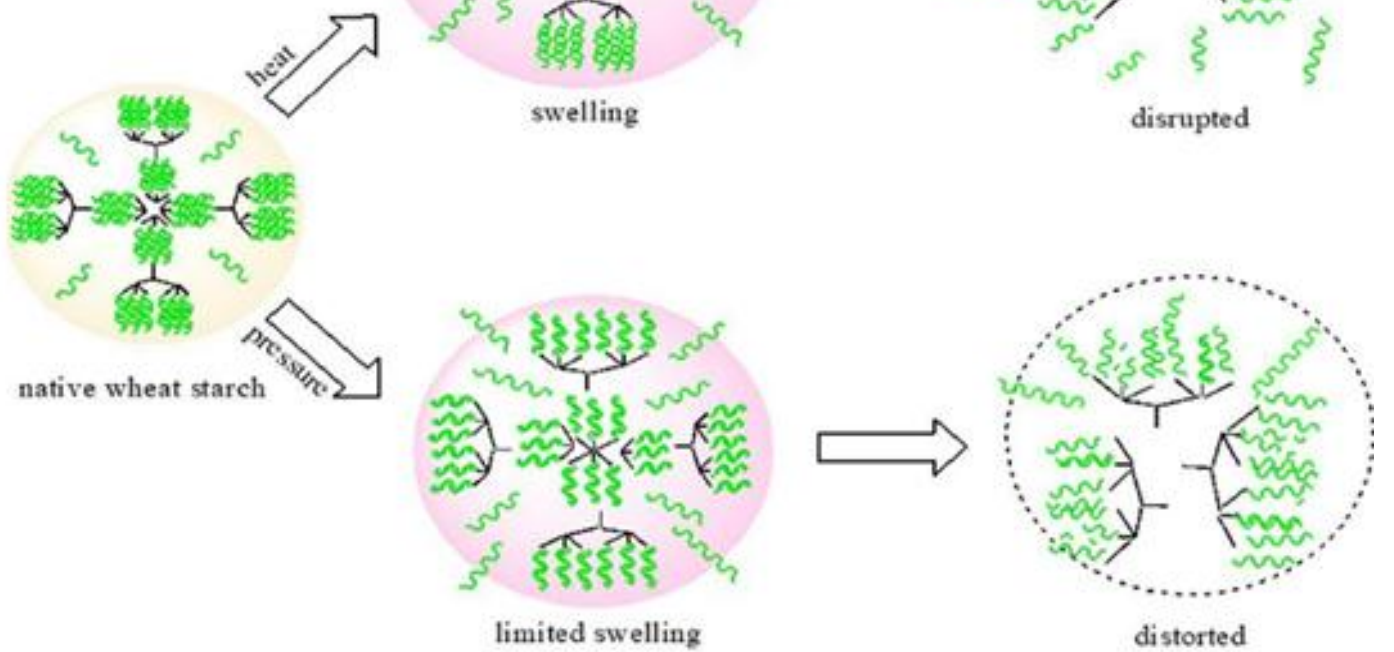

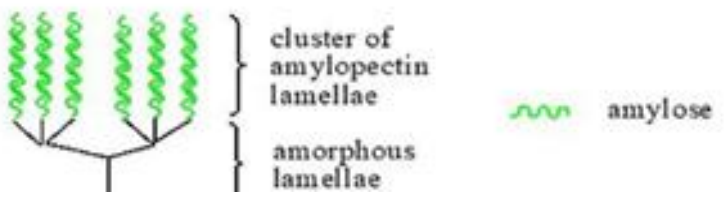

When gelatinized starch is cooled, the segregated amylose-amylopectin molecules realign themselves to a crystalline structure in a process known as retrogradation. Retrogradation is usually accompanied by expulsion of water, an increase in viscosity and gel formation. Furthermore, when retrogradation occurs, amylose links up with multiple glucose units, forming a double helix, and the short chains of amylopectin crystallize simultaneously. As well, components present in the starch granule affect retrogradation.

The resulting product of retrograded starch is the formation of a gel. In native starch with a high amylopectin ratio, the gel formed is typically soft. Contrarily, starch containing a high amylose ratio forms a flexible and strong gel that exhibits resistance to deformation
(Belgacem and Gandini, 2008). Since the soft amylopectin gels display low molecular strength, their desire for industrial use is rather limited (Domingos et al., 2017). Hence, for most industrial applications, starch with high amylose content is preferred.

\section{Factor affecting starch-based biodegradable films}

\section{Amylose and amylopectin content}

The mechanical properties of a starch film are subjective by some factors; starch cultivar, amylopectin to amylose ratio and level of chemical modification or substitution. Amylose is identified to retrograde after gelatinisation into crystal structures (A and Btype) (Miles et al., 1985) and reaches a high final crystallinity in dried films (Rindlav- 
Westling et al., 1998). The crystalline fraction of starch films is recognised to increase with amylose content (Van et al., 1997). Amylopectin forms amorphous films, but it is known to crystallise under definite conditions (Ring et al., 1987).

Films created using amylose are more flexible as compared to using amylopectin. This is because of the linear nature of amylose molecules and their ability to straighten out; as opposed to the highly branched amylopectin that entangle easily. Positive correlations between amylose content and film tensile strength and elongation have been reported (Van et al., 1997). Starch films comprising mixtures of amylose and amylopectin from different cultivars have been reported to co-crystallise and a wide range of film properties result depending on plasticiser and processing conditions (Gudmundsson et al., 1990). As amylose content increased storage modulus increased, crystallinity increased, elongation decreased. Native starch films show a reduction in elongation at break, an increase in ultimate tensile stress and Young's modulus with increasing amylose content. There appears to be a correlation between starch amylose content, film crystallinity and mechanical properties. If the amylose contents are same then hydroxypropyl modification changes the mechanical properties. Thus, film crystallinity increased with increasing amylose content, and an increase in film crystallinity correlated with an increase in Young's modulus and a decrease in elongation at break. Potato starch produced films exhibited low storage and loss modulus and a high damping factor. The relatively low amylose content in potato starch resulted in a low film crystallinity. Potato starch contains a large amount of amorphous amylopectin and hence has a low crystallinity and no regular water channels (Be Miller and Whistler, 2009).
In a study of viscometry changes during starch melt extrusion with various amounts of glycerol plasticiser (20 to $40 \% \quad \mathrm{w} / \mathrm{w})$, amylopectin starch $(75 \%)$ it was reported that storage modulus and loss modulus data decreased significantly when glycerol plasticiser was added at 29 and $33 \%$ w/w. The plasticisation starting point for glycerol in high amylopectin starch was approximately $30 \%$ w/w (Rodrigue-Gonzalez et al., 2004). The mechanical properties of the starch films were dependent on the amylose to amylopectin ratio and overall film crystallinity. Retrogradation is associated with amylose molecules and increase in amylose films results in an increase of retrogradation and thus film crystallinities. It was learnt that the extent of retrograding observed in a gelatinized starch was an issue of its botanical origin and amylose to amylopectin ratio (Fredrikssona et al., 1998). Retrogradation is a complex process, and it has been observed that botanical origin, granule lipid and fat content, hydration level and amylose to amylopectin ratio can all affect the time and degree of observed re-crystallization. Amylose molecules retrograde faster than amylopectin (Gudmundsson et al., 1994).

High amylose starch is favoured for thermoplastic film formation. A comprehensive study by Myllarinen et al., (2002) showed that, while glycerol plasticised amylose films do retrograde and display slight $\mathrm{B}$ and $\mathrm{V}$ type diffusion configurations, their crystallinity is not affected by time and changes in humidity. On the contrary, glycerol plasticised amylopectin films were in the beginning amorphous, but over weeks displayed a continuous development of B type crystallinity. Excitingly, amylopectin films without plasticiser remained amorphous during getting old. Amylose films were also found to be more resistant to acid and water hydrolysis as compared to amylopectin films (Myllarien et al., 2002). Rindlav-Wrestling et 
al., (1998) observed the mechanical properties of amylose and amylopectin films and, prior to Myllarinen, noted the relationship between plasticizers and crystallinity in amylopectin films. They reported that the functional properties of amylose films are superior to those of amylopectin films in respect to film strength and barrier properties. Without the use of plasticisers, thermoplastic starch films are naturally brittle, but plasticised amylopectin systems display improved crystallinity and retrogradation. These observations, coupled with the better water barrier properties of amylose, have driven research towards high amylose content in starch thermoplastics.

The physicochemical and functional properties of starch is significantly affected by the amount of amylose present in the starch. Variation of the amylose content within the same botanical variety is due to differences in geographic origin and culture conditions (Gao et al., 2014). Researchers have given importance to the role of amylose for initial resistance of granules to swelling and solubility, as swelling continues speedily after leaching of amylose molecules. The capacity of amylose molecules of form lipid complexes prevents their leaching and consequently the swelling capacity (Singh et al., 2003). Anhydrous Amylose can form very good films, which are important characteristics for industrial applications. Amylose can form very strong, colorless, odorless and tasteless films (Campos et al., 2011).

Amylose covers a range of degree of polymerization, which is defined as the number of glucose residues per reducing end group and is dependent on the starch varieties. Amylose of potato starch has a degree of polymerization about 6000 glucose units (Hizukuri et al., 1981). Amylose of highamylose corn starch, on the other hand, has a degree of polymerization about 700 (Takeda et al., 1989). In general, the cereal amyloses appear to be smaller than other amyloses (Chen, 1990).

The molecular interaction produced after gelatinization and cooling of the paste is known as retrogradation (Hoover, 2000). Amylose has a tendency to retrograde and is considered primarily responsible for retrogradation of starch. The retrogradation reaction is characterized by ageing followed by markedly enhanced phase, then by a relaxed approach to a limit (Loewus and Briggs, 1957). During retrogradation, amylose molecules associate with other glucose units to form a double helix, while amylopectin molecules re-crystallize through association of its small chains (Singh et al., 2003). After retrogradation, starch reveals lower gelatinization and enthalpy compared to native starch because of its weakened crystalline structure (Sasaki et al., 2000). Initially, the amylose content exercises a strong influence over the retrogradation process; a large amount of amylose is associated with a strong tendency for retrogradation. Amylopectin and intermediate materials influence the retrogradation process during storage under refrigeration; each polymer has a different recrystallization rate (Alay and Meireles, 2015; BeMiller, 2011; Conde-Petit et al., 2001).

Amylose and amylopectin proportion influences the extent of interactions of the polymeric chains comprising the amorphous and crystalline granule fractions. This is the characteristics of each molecule depending on the polymerization degree, length and grade of chain branching, molecular weight and molecular conformation. The swelling capacity of starch is directly associated with the amylopectin content because the amylose acts as a diluent and inhibitor of swelling (Singh et al., 2003). Some species of starch 
that contain amylose-lipid complexes display restricted swelling capacity and solubility (Morrison et al., 1993).

The paste property normally begins $20{ }^{\circ} \mathrm{C}$ lower than its gelatinization temperature ( $\left.\mathrm{T}_{\mathrm{gel}}\right)$, and retrogradation is proportional to the presence of amylopectin (Tan et al., 2006; Yuan et al., 1993). The amylose/amylopectin ratio, the size and shape of the granule, and the presence or absence of lipids and proteins variate in a starch's thermal properties after gelatinization and throughout refrigerated storage (Singh et al., 2003; Tan et al., 2006).

Thermoplastic starch is completeness of gelatinisation during processing, and any succeeding affinity toward retrogradation to form V-type amylose crystals (Chauvan, 2003; Liu and Thompson, 1998). Gelatinisation implicates loss of granular and crystalline structures by heating with water and other plasticizers or modifying polymers (Vermeylen et al., 2006). Retrogradation is due to the recoiling of amylose helical coils. Starch molecules disrupted during gelatinisation slowly re-coil into their native helical arrangements or new single helical conformations known as $\mathrm{V}$ type, which make thermoplastic starch films brittle and cloudy (Gudmundsson, 1994; Karim et al., 2000).

The ability of amylose to produce selfsupporting films has been known for a long time and this is recognised for the ability of its linear chains to interact by hydrogen bonds to a higher extent than the branched amylopectin chains. Amylopectin films, on the other hand, are rather weak due to the higher degree of entanglement caused by the extensive branching and the short average chain length (Rindlav-Westling et al., 1998).

Amylose films had a relative crystallinity of about $30 \%$ whereas amylopectin films were completely amorphous. The combination of amylose and amylopectin results in films with a significantly higher degree of crystallinity. At higher amylose proportions, there is a formation of continuous amylose network which inhibits amylose gelation and hence phase separation. Addition, the amylose network in the films, observed with transmission electron microscopy, consisted of stiff strands and open pores and became opaque as the amylose proportion decreased (Westling et al., 2002).

The effect of amylose enrichment on mechanical, thermal and barrier properties of cassava films were affected by the amylose contents. The amylose enrichment originated from stronger films and this could be explained because during drying of filmforming solutions, water evaporates, allowing the formation of starch networks. During this stage the contiguity of starch chains encouraged by higher amylose contents could simplify the development of matrix with more polymer content per area. The high amylose starch films exhibited better mechanical properties, such as higher modulus and tensile strength, and very high impact strength. High amylose content showed higher glass transition temperature, tensile strength and modulus of elasticity values and lower elongation values than low amylose starch films. There was an increase in thermal and mechanical properties of high amylose starch films (Alves et al., 2007; Ming et al., 2011; Muscat et al., 2012).

Acetylation of starch changes the starch films properties as compared to native starch films except acid solubility. Acetylated high amylose starch film had higher moisture content and water solubility than the native high amylose starch film. Even acetylation of starch alone does not work but the amount of amylose is also necessary. High and medium amylose rice starch have desirable properties whether it is acetylated or native starch but 
low amylose starch is not favourable for making films. As compared to native starch, the acetylation starch decreased the tensile strength and increased the elongation of the films (Colussi et al., 2017).

\section{Type and content of plasticizers}

Natural polymer exhibits fragility and brittleness during thermo-formation which leads to weak mechanical properties with regards to process-ability and end-use application thereby limiting their potential for various applications. Native starch films are brittle compared with synthetic polymers such as polyethylene, and technically need to be plasticized. A plasticizer is a substance that is incorporated into rigid materials to increase its flexibility, workability, and dispensability. Generally, two types of plasticizers are distinguished. To overcome the limitation of natural polymers, the use of various types of plasticizers has gained momentum quite recently. Plasticizers are of low molecular weight, relatively non-volatile organic molecules that increase workability and durability of polymers since they help in the reduction of polymer-polymer contact leading to decrease in rigidity of the three dimensional structure of polymers thereby improving the deformation ability without rupture (Mekonnen et al., 2013; Banker, 1966).

There are two types of plasticizers i.e. external plasticizers and internal plasticizers. External plasticization is obtained by adding an agent which modifies the structure and energy within the three-dimensional arrangement of the film polymer. In which external plasticizers are low volatile constituents added to polymers. These plasticizers are not chemically attached to polymer chains by primary bonds, although there is interaction between the two. Since they are not chemically bound they are easily lost by extraction, migration or evaporation. Conversely, internal plasticizers are an integral part of the polymer chain, which can either be reacted with the native polymer or co-polymerized into the polymer arrangement. Internal plasticization is a result of modifications to the chemical structure of polymers. These plasticizers eventually become a part of the final product. The bulky structure of the internal plasticizers offers more space for the polymers to move and also prevents them from coming close together, thereby softening the polymers by reducing the glass transition temperature $\left(\mathrm{T}_{\mathrm{g}}\right)$ and ultimately elastic modulus. Compared to internal plasticizers, the use of external plasticizers gives the opportunity to choose the right material according to the desired product properties (Vieira et al., 2011; Banker, 1966).

Plasticizers may be categorized as primary and secondary plasticizers. Primary plasticizers those in which at high concentration polymers are soluble. These plasticizers gelatinize the polymer speedily in the regular processing temperature range. These plasticizers are considered the sole plasticizer or as the core component of the plasticizer. They should not leach out from the plasticized material. Whereas, secondary plasticizers have limited compatibility with the polymer and reduced gelation capacity. They are generally combined with primary plasticizers to cut the cost or increase product properties (Tyagi and Bhattacharya, 2019).

Plasticizers have linear or cyclic carbon chains with an average molecular weight of 300 to 600 . These are high boiling point liquids with a low molecular size that comforts them to enter into the intermolecular voids in the polymer chains leading to depressing of secondary forces between the chains. This changes the three- dimensional network of the polymer chains which 
ultimately provides greater mobility by increasing the free volumes. Therefore, the chemical structure of the plasticizer along with the molecular weight, functional groups, chemical composition plays an important role in determining the degree of plasticity of polymers (Vieira et al., 2011).

The compatibility of the plasticizer and the polymer play a key role in various parameters such as solubility, polarity, dielectric constant and hydrogen bonding (Vieira et al., 2011).

It is desirable to have low vapour pressure and diffusion rate of plasticizer into the polymers. This perpetuity of plasticizers is associated with volatility and resilient to movement in and removal from water, oil or any other solvents.

Easiness and difficulty of processing of polymers are tackled by addition of plasticizers. The plasticizers concentration and type helps in modifying the properties of the polymer as well as stimulate the processing ability by reducing viscosity, heat generation and power consumption and improving dispersion and flow characteristics. Plasticizers help in reducing brittleness/fragility and augment flexibility in films making them easier to handle, along with preventing cracks and pores in them.

Finally, the selection of plasticizer for a specific polymeric system depends on their compatibility with each other, preferred features of the final product, plasticization properties, migration/permanence, toxicity and cost.

Starch as it is not used directly for plastic film due to its hydrophilicity and lower mechanical and tensile properties, plasticizers are used to increase film flexibility and to reduce internal hydrogen bonding between polymer chains while increasing molecular space. Dried starch has higher glass transition temperature $\left(240^{\circ} \mathrm{C}\right)$ than its thermal degradation temperature $\left(220^{\circ} \mathrm{C}\right)$. This higher glass transition temperature is because of strong intermolecular and intramolecular hydrogen bonding between the starch macromolecules. If plasticizer is not used for thermoplastic starch polymers derivation then they are very water sensitive and can undergo significant molecular weight change during processing. Therefore, plasticizers are incorporated to make starch modification for the breakdown of the crystalline granules and decrease the glass transition temperature $\left(\mathrm{T}_{\mathrm{g}}\right)$ and melting temperature $\left(\mathrm{T}_{\mathrm{m}}\right)$ (Talja et al., 2007). Plasticizers used in starch films are polyols. Generally sorbitol and glycerol are used for this purpose. Increase of glycerol concentration reduces the glass transition temperature which is related to hydrophilicity of this glycerol. Glycerol plasticizers expose hydrophilic hydroxyl groups for adsorptions of water molecules in starch films on its active sites. Because of low molecular weight and plasticizing effect of water, its addition to starch films, acts as a mobility enhancer and an escalation in molecular mobility of amorphous and partially crystalline polymers due to an increase in free volume thus, decreasing glass transition of films (Mekonnen et al., 2013).

Starch granules are not soluble in cold water due to the fact that strong hydrogen bonds hold the starch chains together. However, when starch is heated in water, the crystalline structure is disrupted and water molecules interact with the hydroxyl groups of amylose and amylopectin, producing the partial solubilisation of starch (Hoover, 2001).

Though water is a good plasticizer it is not used alone as it gives a brittle product when equilibrated with ambient humidity (Forssell et al., 1997; Forssell et al., 1999) and due to evaporation of water. Many modifiers have 
been used to plasticise starch including; glycerol (Alves et al., 2007; Fama et al., 2006; Fama et al., 2007; Jangehud and Chinnan, 1999; Mali et al., 2006; Parra et al., 2004; Setiawan et al., 2010), water ( $\mathrm{Li}$ and Huneault, 2011), urea (Sjoqvist and Gatenholm 2007), ethanolamine (Ma and $\mathrm{Yu}$ 2004; Ma et al., 2006) formamide (Zheng et al., 2009), polyethylene glycol (Parra et al., 2004) and sorbitol, mannitol as well as sugars (Kechichian et al., 2010; Talja et al., 2008; Viega-Santos et al., 2008; Averous et al., 2000). Other small polyols such as ethylene glycol, sorbitol, maltose and xylitol have been successfully employed as starch film plasticisers (Lourdin et al., 2003; Da Roz et al., 2006; Zullo and Iannace, 2009). Sorbitol behaves similarly to glycerol and exhibits an anti-plasticizing effect at low volume fractions (<27\% w/w) (Gaudin et al., 1998). Starch film modulus decreases with smaller plasticiser molecular weight, provided the volume is above the anti-plasticization threshold. The exception to this is xylitol, which can crystallize and has been observed to increase a starch film's Young's modulus (Talja et al., 2007). The use of polyols as a film plasticiser changes water sorption and transmission properties (Talja R. A., 2007). Sucrose has also been successfully utilized as a starch plasticiser, with reporting improved elongation and reduced modulus in cassava starch films (Veiga-Santos et al., 2007).

High molecular weight polar polymers can also act as pseudo starch plasticisers, the most commonly employed being polyethylene glycol (PEG) and polyvinyl alcohol (PVOH). PEG addition in a starch film rises elongation whereas reducing tensile strength, and water barrier properties, which results in a more flexible, softer water soluble film (Bourtoom T., 2008). PEG is only suitable as a plasticiser for starch when used at a molecular weight below $8000 \mathrm{~g} / \mathrm{mol}$, as above this molecular weight PEG and starch undergo miscibility changes resulting in PEG 'pooling' with a net loss of plasticizing effect (Kim et al., 2009). Whilst PVOH addition in a starch film is technically a blend, it does have a small plasticizing effect, increasing film elongation and flexibility (Cinelli et al., 2005).

Many new and novel plasticisers have also been suggested and tested in thermoplastic starch systems. Use of both formaldehyde and urea as a starch plasticiser, generates good results with improved elongation and mechanical properties as well as a decrease in observed retrogradation (Ma et al., 2006; Ma et al., 2005). Use of $30 \%$ ethylene-bis formamide by volume as a plasticiser for corn-starch based films increases elongation at break up to $264 \%$ (Yang et al., 2006). This work was expanded on use of N,N-bis(2hydroxyethyl) formamide plasticiser with starch, resulting in a decrease in film glass transition temperatures and removal of X-ray diffraction crystalline features. At low humidity, the elongation at break was comparable with an equivalent volume of glycerol and at high humidity the elongation was superior (Dai et al., 2008).

All of these plasticisers have hydroxyl groups allowing compatibility with starch granules and they plasticise starch by breaking the internal hydrogen bonding between the glucose rings in starch.

Strong intermolecular and intramolecular hydrogen bonds link the macromolecular chains of amylose and amylopectin in native starch. Starch-starch interactions are replaced by starch-plasticizer interactions. The plasticiser at high temperatures $\left(90^{\circ} \mathrm{C}-180^{\circ} \mathrm{C}\right)$ converts starch granules to plasticized moldable thermoplastic material called thermoplastic starch, enabling it to be extruded, pressed or injection moulded, dissolving starch granules and lowering its melting temperatures. Breaking up the starch 
granules results in an increase of macromolecular chain mobility and consequently the material softens and becomes less brittle. The semi-crystalline granules are converted into a homogeneous and amorphous material, which is known as the plasticisation of starch (Averous and Halley 2009; Zhang et al., 2004).

Various mechanisms for the plasticisation of starch have been proposed. These include lubricity theory which suggests the plasticiser expedites the mobility and movement of starch macromolecules over each other, while the gel theory supposes the plasticisation is a result of the disruptions that occur in-between polymer interactions due to either hydrogen bonds and van der Waals or ionic forces. The free volume theory considers that the free volume between polymer chains increases by the addition of a plasticiser causing a decrease in the glass transition temperature. In all of these theories the main role of a plasticiser is to intervene between starch chains and reduce the internal interaction between starch chains and these are replaced by starch-plasticiser interaction (Zhang et al., 2014; Gioia and Guilbert, 1999; Mohammadi Nafchi et al., 2013).

An effective plasticiser needs to be polar, hydrophilic and small enough to fit between the starch chains. Additionally, the boiling point of the plasticiser should be higher than manufacturing conditions so that it does not evaporate during processing (Zhang et al., 2014). Water and glycerol are the most common and effective plasticisers as they can be inserted easily into starch Zhang et al., 2014; Gioia and Guilbert, 1999; Mohammadi Nafchi et al., 2013). Some plasticisers such as urea, formamide and ethylene bis formamide contains amide functionalities have proved to act as good plasticisers (Zhang et al., 2014; Ma and Yu 2004; Huang et al., 2006; Yang et al., 2006a; Yang et al., 2006b; Wang et al.,
2008). Low glycerol contents can be used to plasticise a film, as long as glycerol favourably occupies water binding sites during film formation (Godbillot et al., 2006). Anti-plasticizing effects were only noticed in films with low water content, and that in films with high water content glycerol behaved as a typical plasticiser. The exact interactions between starch-water-glycerol are as yet unknown and appear to differ between starch of various botanical origin, water content and processing conditions (Chang et al., 2006).

The stability of a plasticizer is also of highly significance since this influences the physical and mechanical strength of the film. The plasticizer should be stable and its degree of retaining by the film should be high. Other properties, such as its chemical stability, hygroscopicity, colour, flavour, and so on, are also more or less important depending on the type of film under consideration. In addition, the content of plasticizer necessarily varies from $10-60 \%$ (dry basis) according to the nature and type of film and the method of application (Yang and Paulson, 2000).

Talja et al., (2007) observed the effect of various polyols and polyol contents on physical and mechanical properties of potato starch-based films. Plasticizers, such as glycerol, sorbitol or xylitol, are typically used for decreasing the brittleness. At low glycerol concentrations both strain and strength decreased but above $20 \%$ glycerol concentration the elongation reached larger values. Effects of glycerol, sorbitol or xylitol on physical and mechanical properties of starch films were largest for glycerol and smallest for sorbitol. High contents of xylitol and sorbitol resulted in changes in physical and mechanical properties of films probably due to phase separation and crystallization.

Sorbitol plasticized films produced the films with highest mechanical resistance, but the 
reduced film flexibility. In contrast, glycerol and polyethylene glycol plasticized films displayed flexible structure; however, the mechanical resistance was low, while inversely affecting the water vapor permeability (Bourtoom and Chinnan, 2008a).

Dai et al., (2010) reported that increasing the plasticizer content resulted in increasing water vapor permeability of the resulting film due to structural modifications of the starch network brought about by the plasticizer associated with the hydrophilic character of plasticizer, which preferred the absorption and desorption of water molecules. Plasticizers reduced intraand intermolecular forces in starch. In addition, plasticizers could extend, dilute and soften the structure effectively; then the starch chain mobility would be increased. An increase in inter chain spacing due to the inclusion of glycerol molecules between the polymer chain may promote water vapour diffusivity through the film and hence accelerate the water vapour transmission (Yang and Paulson, 2000).

\section{Type and content of lipids}

The addition of lipophilic materials can significantly modify starch film properties by increasing the film's hydrophobicity and improves the barrier properties of starch films to water vapour (Jimenez et al., 2012; García et al., 2000a). The proportion of lipid depends on the use of the film and it is a balance between the hydrophilic-hydrophobic ratio and the crystalline-amorphous ratio (García et al., 2000a). Biodegradable starch films generally have good barrier properties against oxygen at low and intermediate relative humidity, and have good mechanical properties, but poor barrier properties against water vapour due to their hydrophilic nature (Kester and Fennema, 1986). Whereas, films prepared with lipid materials have good water vapour barrier properties, but are usually opaque and relatively inflexible. Because they are solids at room temperature, some lipids also require the use of solvents or high temperatures to prepare films by casting technique. Long-chain molecules of lipids are partially water soluble. Unsaturated fatty acids have significantly lower melting point and increased moisture transfer rates as compared to saturated ones. Waxes produce the best water vapour barrier properties, but produce fragile and/ or brittle films. Lipid compounds like neutral lipids, fatty acids, waxes, and resins are generally used for the preparation of lipid-based biodegradable films (Kester and Fennema, 1986; Hernandez 1994; Peroval et al., 2002; Muscat et al., 2014; Galus and Kadzinska, 2016). Addition of hydrophobic components such as lipid and wax materials with starch may add a better water vapour barrier in composite starch-lipid films. A composite starch-lipid film has acceptable structural integrity imparted by the starch materials and good water vapour barrier properties contributed by the lipid materials (Greener and Fennema, 1989).

The efficiency of the lipid materials in composite films depends on its proportion and the nature of the lipid used such as structure, chemical arrangement, crystal type, shape, size, distribution of lipids, nature of barrier components, the film structure (including homogeneity, emulsion, multilayer.), and thermodynamics such as temperature, vapour pressure, or the physical state of water in contact with the films (Rhim and Shell Hammer, 2005). Haggenmaier and Shaw (1990) investigated the effect of stearic acid concentration on the water vapour permeability of hydroxypropyl methylcellulose composite films. It was found that the water vapour permeability of the composite films decreased about 300 times with the addition of $40-50 \%$ of stearic acid. However, excessive levels of lipid materials result in the film brittleness. 
In a study of gellan/lipid composite films through emulsification and determining the effect of lipid (beeswax and blend of stearic palmitic acids) on the moisture barrier, and mechanical and optical properties of the films. beeswax was more effective than stearicpalmitic acids in reducing the water vapour permeability and films with beeswax showed better mechanical properties overall than those with stearic-palmitic acids (Yang and Paulson, 2000). Srinivasa et al., (2007) studied the effect of fatty acids (stearic and palmitic acids) on the mechanical and permeability characteristics of chitosan films. No considerable differences in water vapor permeability were observed in fatty acid blend films. There is no significant effect on water vapour permeability for fatty acids (stearic and palmitic acids) blends with chitosan film.

Addition of lipids in rice starch-chitosan composite film increased elongation at break and decreased the tensile strength and water vapour permeability. The increase in the lipid proportion results in a partial replacement of lipids in the film matrix. The interactions between the polar polymer molecules are higher than the interactions between nonpolar lipid molecules and between the polar polymer and nonpolar lipid molecules. The differences in mechanical and barrier properties between starch-lipid composite films could be related to their physical state, structure, and chemical nature of the lipids. Such as, rice starch-chitosan films added with oleic acid provided the films with smoother surface and higher values of tensile strength and elongation at break but lower water vapour permeability than with margarine and palm oil, respectively (Bourtoom and Chinnan, 2009).

Starches are known to have poor moisture barrier properties due to their hydrophilic nature. Incorporation of hydrophobic phase constituted by lipid into starch matrix reduces water sorption and water transfer through films. Lipid incorporation is expected to increase the hydrophobicity of these films, to reduce the water vapour permeability (Kowalczyk and Baraniak, 2014; RoccaSmith et al., 2016). Nature of the lipids, the chain length of the fatty acids and its specific structure, chemical arrangement, physical state (solid or liquid) and interactions with other starch components determines the water vapour barrier efficiency of film matrix. Lipid particle size also has an effect on film water vapour permeability, generally lowering this parameter. Incorporation of lipids into a film results in a large number of spherical particles uniformly dispersed throughout the matrix, which increases the distance a permeating molecule must travel to pass through the film. However, even though lipids can lower water vapour permeability, they normally have a negative impact on film mechanical properties since they interact only minimally with starch (Peroval et al., 2002). Various studies have shown that lipids do not form cohesive and continuous matrices (Rhim et al., 1999; Yang and Paulson, 2000; Peroval et al., 2002). Candelilla wax was also used in a study on the surface qualities of biopolymer-based films (carboxymethylcellulose, oxidised potato starch, soy protein and gelatin) (Kowalczyk and Baraniak, 2014). The resulting films had irregular surfaces compared to the smooth homogeneous surfaces of the wax-free films. Moreover, addition of candelilla wax decreased film mechanical properties no matter the biopolymer type used. The wax significantly decreased water vapour permeability in the films (Castro-Rosas et al., 2016).

Adding saturated fatty acids to corn starch films did not notably improve the water vapour transfer of non-aged films and saturated fatty acids only provoked a slight reduction in water vapour permeability as 
compared to oleic acid (Jiménez et al., 2012; Fakhouri et al., 2009). Conversely, García et $a l$. , (2000a) observed that due to the migration of the sunflower oil and the decrease of the crystalline-amorphous ratio, increase of the sunflower oil concentration above a critical ratio, the water vapour permeability of starch films also increases. It was also observed that films containing oil showed lower fusion enthalpy values, which were associated with a lower crystalline-amorphous ratio. Starchfatty acid films also developed crystallinity with ageing, which implied an increase in the film's stiffness and brittleness and a loss of stretchability, gloss, and transparency (Jimenez et al., 2012).

\section{Relative humidity}

Generally, moisture content of the films was seen to be influenced by relative humidity. Films stored at high relative humidity conditions contained higher amounts of moisture or water compared to films stored at lower humidity conditions. Biodegradable starch films generally provide a good barrier against oxygen at low and intermediate relative humidity, and have good mechanical properties, but their barrier against water vapour is poor due to their hydrophilic nature (Kester and Fennema 1986). It was reported that when the relative humidity of surrounding films increased this yielded increasing water content. When the water content in the films increases this provides an increasing movement of molecules in the network allowing swelling with resulting heterogeneous network structure. Hence, sharply decreased storage modulus and glass transition temperature and increased the oxygen permeability of the resulting films. (Standing et al., 2001).

It has been reported that temperature and relative humidity induce physical and chemical changes in edible films that cause structural changes in films resulting in alterations in the barrier and mechanical properties of films. At high relative humidity, the water diffusion rate showed higher in the starch nanocomposite films. It seemed that there was more water sorption and diffusion in the starch matrix due to its initially high swelling capacity and high chain mobility. Even the oxygen permeability coefficient slightly increased in the range of relative humidity between 30 to $45 \%$ and greatly increased at higher relative humidity (Masclaux et al., 2010).

For cassava starch-soy protein film tensile strength increased slightly with increase in temperature at a constant relative humidity but decreased with increase in relative humidity. Higher elastic modulus was obtained at higher temperature and low relative humidity in a cassava starch-soy protein film. Elongation at break increased with higher relative humidity and lower temperature. On the other hand, tensile strength and elastic modulus increased slightly with increase in temperature at a constant relative humidity while elongation at break decreased. This behaviour could be attributed to film moisture content. Increase in relative humidity, increases the film moisture content because of moisture adsorption and hence it resulted in decrease of tensile strength and elastic modulus of edible films (Chinma et al., 2015).

At high relative humidity in starch film starch crystallinity increases and hence it decreases in elongation at break. Amount of water absorbed by food materials at constant relative humidity decreases with increase in temperature. This indicates that less water was bound at higher temperatures decreasing film plasticizing and causing strengthening of film structure thereby improving tensile strength and elastic modulus of the films. Also, it could be inferred that increasing 
temperature, increased the effect of relative humidity on the films (Van Soest et al., 1996).

Up to temperature of $40{ }^{\circ} \mathrm{C}$ and $80 \%$ relative humidity, water vapour permeability of the films increased with increase in temperature and relative humidity. Water vapour permeability is a phenomenon that implies water solubility and diffusion of the water molecules through the medium of the film (Oses et al., 2009). The increase in water vapour permeability of edible films prepared from blends of cassava starch and soy protein concentrates with increase in temperature and relative humidity may be due to high moisture contents of the films due to moisture adsorption at high relative humidity.

Kaya and Maskan (2003) reported that temperature and relative humidity increased the water vapour permeability of edible films prepared from pestil fruit and starch.

Othman et al., (2019) reported that relative humidity and temperature play an important role in determining the water sorption and mechanical properties of starch and starchchitosan nanoparticle films. Water molecules were absorbed into the stored files faster at high relative humidity condition than the films stored at low relative humidity condition. This was because of the saturated water molecules at high relative humidity condition, thus increasing the rate of adsorption of water molecules in the surrounding into the films (Othman, et al., 2017). Equilibrium moisture content of the film requires more time at high relative humidity as compared to low relative humidity. It was reported that saturated water molecules in the surrounding also lead to the longer time for the water sorption activity to reach equilibrium. Hence, the time required for the moisture content to reach equilibrium increases with increasing relative humidity
(Othman et al., 2017, Suppakul et al., 2013). Even saturated water molecules in the surrounding also result in high kinetic energy, thus increasing the sorption of the water into the films (Othman et al., 2017). This resulted in an increase in the rate of sorption and water adsorption capacity with an increase in relative humidity whereby the films absorbed faster and stored more water when kept at high relative humidity surroundings (Mali et al., 2005). It was recommended that for reducing the water sorption rate and water adsorption capacity hence increasing stability and shelf life of both the films, the films need to be kept at both low relative humidity and high temperature. It can be inferred that at high temperature and high relative humidity condition, the lower are the chances to check auto oxidation and the higher the chances of the film to turn out to be unsteady. Accordingly, for high temperature conditions, it is recommended for the films to be kept at as low relative humidity as possible to evade auto oxidation (Othman et al., 2019).

Tensile strength for starch film and starchchitosan nanoparticle film were found to decrease with the increase in relative humidity except for starch films at temperatures of $4^{\circ} \mathrm{C}$ and $30^{\circ} \mathrm{C}$. At this temperature, tensile strength decreased with the increase in relative humidity from $23 \%$ to $50 \%$ and then increased with the increase in relative humidity from $50 \%$ to $75 \%$. Reduction of tensile strength with the increase in relative humidity was observed because as the moisture equilibrium increased at high relative humidity, the concentration of water absorbed by the films increased thus resulting in a plasticizing effect in the film medium (Othman et al., 2019). Mali et al., (2005) also reported at high relative humidity equilibrium moisture content is also high and hence it exerts plasticizing effect and mobilizer enhancer which results in decrease in tensile strength with the increase in relative 
humidity. Though, if the concentration of water is too high at high relative humidity conditions, the water cannot exert a plasticizing effect on the film; thus, it will increase the tensile strength (Suppakul et al., 2013).

For starch films, at $4^{\circ} \mathrm{C}$ and $30^{\circ} \mathrm{C}$, elongation at break seems to increase with the increase in relative humidity from $23 \%$ to $50 \%$ and decrease with the increase in relative humidity from $50 \%$ to $75 \%$. This trend is inverse to the trend of tensile strength. For cassava starch based films there is an inverse relation between tensile strength and elongation at break (Othman et al., 2019, Othman, et al., 2017; Tongdee Soontorn et al., 2011).

Number of hydrogen bonding between starch chains results in increase in tensile strength and decrease in elongation at break because of reducing the molecular mobility of the starch films.

This is also understood by the same reasoning of plasticizing and antiplasticization effects. Relation between relative humidity is in proportionally with elongation at break because as the moisture equilibrium increased at high relative humidity, the concentration of water absorbed by the films increased which ensuing to plasticizing effect in the film matrix (Othman et al., 2019). However, at too high concentration of water in surroundings, the water exhibits as antiplasticizer on the film; thus, its effect on the tensile strength is proportionally (Suppakul, et al., 2013) and on the elongation at break is inversely.

Addition of chitosan nanoparticle or carboxymethyl cellulose in starch film elongation at break decreased and tensile strength increased slightly with the increase in relative humidity as compared to starch films. The increasing of tensile strength of the starch films with increasing concentration of chitosan nanoparticle or carboxymethyl is likely attribute to the formation of intermolecular interaction between hydroxyl group of starch with carboxyl group of chitosan nanoparticle or carboxymethyl cellulose. During the processing and drying of the composite films, the original hydrogen bonds formed between starch molecules could be replaced by new hydrogen bonds formed between the hydroxyl groups in starch molecules and the hydroxyl and carboxyl group of additional composite material (Othman et al., 2019; Tongdee Soontorn et al., 2011). In starch films elongation at break decrease and tensile strength increase due to the increase in starch crystallinity induced by the high relative humidity (Chinma et al., 2015). Accordingly To decrease in elongation at break was due to the antiplasticization effect of the high level of water plasticizer indicating stronger interactions between the water and amylose and amylopectin in biopolymer that induced a loss of macromolecular mobility (Suppakul et al., 2013). The plasticizing effect of water decreased with the increase of relative humidity due to the increment in water absorption of the film.

Young's modulus or elastic modulus is the important measure of the film stiffness or rigidity of the material. High Young's modulus indicates high stiffness of material. Overall, Young's modulus of starch and starch-chitosan nanoparticle films decreased with the increase in relative humidity from 23 to $50 \%$ and then increased with the increase in relative humidity from 50 to $75 \%$ except for starch films at $40^{\circ} \mathrm{C}$. The decrease in Young's modulus when relative humidity was increased from 23 to $50 \%$ was due to the increase of water absorbed by the films and thus lowering the hydrogen bonding between the film molecules which made the films to become less stiff. In the meantime, as earlier 
deliberated, at higher concentration of water surroundings (relative humidity $75 \%$ ), the water cannot exert a plasticizing effect on the film thus decreasing the elongation at break and increasing Young's modulus since the films became more stiff (Othman et al., 2019).

\section{Starch blends with synthetic polymer}

Mixing two polymers of different molecules or monomers in any ratio is called blend. Blend can span from completely compatible to incompatible, and blend morphology is subject to a large number of factors from compatibilizers, kinetic and equilibria phenomenon through to annealing and shear application during processing (Billmeyer, 1984). Starch, an omnipresent bio-material, has the unique property of biodegradability and easily dissolves in water. Blends of synthetic polymers and starches have been extensively studied since these blends can be prepared so they are biodegradable. Starch film has various disadvantages like brittleness without suitable plasticizers, hydrophilic nature and poor water resistance, deterioration of mechanical properties upon exposure to humidity, and soft and weak nature in the presence of plasticizers.

Thus, starch needs to be blended with other synthetic polymers to exclude these shortcomings. Though, most of the synthetic polymers are hydrophobic and thermodynamically immiscible with hydrophilic starch, hence simple mixing will result in phase mismatch and poor mechanical properties. Simple mixing of starch with other polymers is referred to as composites. Preferably, starch and the second polymer should be covalently bonded through existing functional groups or by introduction of new functional groups. This reactive mixing is referred to as blends. In simple mixing there is no phase separation if the starch present is below certain levels in the composites. Below this critical level, the weakening in properties has been found to be insignificant. For example in starch-polyester composites, this critical level is approximately $25-30 \mathrm{wt} \%$.

Synthetic polymers that have been reactively blended with starch have carboxyl, anhydride, epoxy, urethane, or oxazoline functional groups that can react with the hydroxyl or carboxyl groups in native and modified starches, respectively. Synthesizing starchbased blends is a method of graft copolymerization. Synthetic monomers are covalently bonded to hydroxyl positions on starch and then polymerized to produce starch graft copolymers.

Common blending polymers are polyethylene (PE), polyester, polyvinyl alcohol (PVOH), polypropylene (PP), polylactic acid (PLA), polyurethane (PU), poly (3-hydroxybutyrate) (PHB) and various other polyesters.

\section{Polyethylene}

Starch is a highly hydrophilic macromolecule. It is used as the degradable additive in the preparation of biodegradable polyethylene film having properties of resistance to microbial breakdown. The biodegradation is a function of molecular size in which the higher molecular size, the smaller possibility of biodegradation. Starch and polyethylene have different properties which results in poor compatibility of starch/polyethylene blends (Shujun et al., 2006). Glycerol has an interfacial effect between polyethylene and starch, in which a thin glycerol rich layer is formed at the polyethylene-starch edge. This layer is jointly miscible with both phases and leads to greater compatibility and mechanical properties (Taguet et al., 2009). The dry native starch blends with polyethylene are used for many products (Shujun et al., 2006).

The degradation of the carbon-carbon backbone may be enhanced by addition of 
readily biodegradable compounds, such as starch, to a low-density polyethylene matrix. The rate of biodegradation of starch-filled polyethylene depends on starch content and is very sensitive to the environmental conditions. The biodegradation of $\mathrm{PE} / \mathrm{starch}$ blends suggests that microbes consume starch and create pores in the materials, leading to increases in the surface areas of the PE matrixes and providing susceptible groups for their biodegradation (Jayasekara et al., 2005; Arevalo, et al., 1996; Griffin, 1976; Park et al., 2004).

In the case of thermoplastic starch blend with polyethylene (Low density polyethylene (LDPE) and Linear low density polyethylene (LLDPE)) the modulus decreased as expected with addition of thermoplastic starch. The blends containing 22\% TPS in LDPE and $39 \%$ TPS in LLDPE maintained high elongation at break at these high loading. The morphology showed the unsuitability in TPS/PE blends.

Addition of a functional group to modify polyethylene improves the films made from blends of starch-polyethylene. Modified LDPE by addition of maleic anhydride improves the biodegradability for starchLDPE blends. Similarly modified HDPE by addition of maleic anhydride improves the mechanical properties of starch-HDPE blends. Blending of chemically modified LDPE with glycidyl methacrylate content improved the mechanical properties of starch-LDPE blends as compared to LDPE modified by maleic anhydride. In a study on effects of glycerol and PE-g-maleic anhydride content on properties of TPS/LDPE blends, it was found that the interfacial adhesion between TPS and LDPE was improved by the addition of PE-gmaleic anhydride (Wang et al., 2004). During the study of microstructural morphologies of starch/polymer mixtures, It was seen in SEM diagrams that increasing starch loading in
starch/LDPE blends decreases the interfacial adhesion and homogeneity (Park et al., 2004). An increase in the starch content in LDPE starch blends resulted in higher gas permeabilities, so the biobased materials might be good alternatives for packaging of highly respiring foods (Petersen et al., 2001). In a study on blends of potato starch with commonly used plastics such as LDPE with addition of an ionomer, the elongation at break and modulus showed the same trend with variation of starch loading. This can be explained by the lack of good phase adhesion, as well as poor dispersion (Park et al., 2004).

Blending of chemically modified HDPE with glycidyl methacrylate content improved the mechanical properties of starch-HDPE blends. For improvement of the compatibility of the blends, blending of TPS with PE was carried out in presence of a compatibilizer (HDPE-gmaleic anhydride). It was found that the carboxyl groups in the compatibilizer react with hydroxyl groups in TPS, which improved the mechanical properties of the blend especially elongation at break and impact strength (Taguet et al., 2009). TPS with recycled HDPE. The addition of TPS to recycled HDPE increased the melt flow index. Also it was found that the addition of $30 \%$ of TPS reduced the tensile strength SEM study confirmed the poor adhesion and interfacial interaction between HDPE and TPS in the prepared blends.

The impact strength of the blends of poly (ethylene-co-vinyl alcohol) as a compatibilizer in TPS/ LDPE blends was improved by the addition of a compatibilizer even with a high TPS loading of 40 and $50 \%$ (Sailaja and Chanda, 2002). Mechanical properties were significantly improved by using LDPE-g-dibutyl maleate (LDPE-gDBM) in LDPE/TPS (Girija and Sailaja (48)). Use of azodicarbonamide as a foaming agent mechanical properties of TPS/LDPE blends 
decreased after the foaming process and they were completely biodegradable after two months of burying (Senna et al., 2007). The enzymatic degradation of TPS was completely $(100 \%)$ after $48 \mathrm{~h}$ while LDPE/TPS (38/62) reached its maximum degradation (nearly 96\%) in $72 \mathrm{~h}$, and LDPE/TPS (68/32) reached its maximum degradation (nearly 69\%) after $72 \mathrm{~h}$, the results of this study confirm that the degradation was in TPS phase (Salcido et al., 2008).

In a study of influence of maleic anhydride on the compatibility TPS/LLDPE blends, the morphological, rheological and dynamic mechanical thermal properties were truly improved (Wang et al., 44). The TPS/LLDPE films exposed to air demonstrated more obvious degradation than films buried in soil and films exposed to air experienced light oxidation degradation. Also it was found that the biodegradation of the film took place when it was buried under moist soil, but the velocity of the light oxidation degradation was higher than that of the biodegradation (Wang et al., 2006). Citric acid enhanced the mechanical properties of as well as fluidity of TPS/LLDPE blends (Wang et al., 2007).

\section{Polyester}

In an investigation carried out by Tokiwa and Iwamoto (1994), blends of starch and polyester are completely biodegradable when each component in the blend is biodegradable, as well as compostable. The type of microorganisms and their populations are the main factors influencing the degree of degradation. It is well-known that the addition of starch filler improves the rate of degradation of polyesters (Ratto, et al., 1999). Mani and Bhattacharya (2001) reported that biodegradable blends of starch and aliphatic polyester give excellent properties when small amounts of compatibilizers (anhydride functionalized polyesters) are added. The tensile strengths are comparable to that of the synthetic polyester, even at a starch level of $70 \%$ by weight. The elongation is drastically reduced as the percentage of starch is increased.

\section{Polyvinyl alcohol}

Starch-polyvinyl alcohol blend is water soluble, low cost and is available with different molecular weights. Starch-polyvinyl alcohol blends has better properties of tensile strength and elongation at break than starch films, and the blend ratio as well as polyvinyl alcohol molecular weight can be adjusted to create desired mechanical properties (Mao and Imam, 2000; Fishman and Coffin, 2006). However polyvinyl alcohol blend reduces the biodegradation rate (Russo et al., 2009).

Park et al., (2004) reported that the film containing citric acid was better than glycerol or sorbitol, because hydrogen bonding at the presence of citric acid with hydroxyl group and carboxyl group increased the inter/intramolecular interactions between starch, polyvinyl alcohol and plasticizers.

Yoon et al., (2006) studied the effect of functional groups type of the plasticizers on the properties of starch/polyvinyl alcohol blends. Glycerol, succinic acid, malic acid and tartaric acid were used as plasticizers. The results of measured tensile strength and elongation verified that hydroxyl and carboxyl groups as functional groups enhanced the flexibility and strength of the film. When the additives containing both hydroxyl and carboxyl groups were simultaneously added, the tensile strength and elongation were better than in glycerol added film with hydroxyl groups only.

Sreedhar et al., (2006) prepared starch/polyvinyl alcohol blends crosslinked 
with epichlorohydrin using different plasticizers such as PEG and glycerol. Cross linking resulted in a decrease in glass transition temperature as well as damping parameter values of the blends. The authors inferred that this lowering was due to the decrease in the regularity of the $-\mathrm{OH}$ groups on crosslinking. The thermal stability and activation energy of thermal decomposition were found to pass through maximum at a critical concentration of plasticizer and increases with increasing crosslinker concentration.

Zhou et al., (2009) prepared and characterized surface crosslinked TPS/polyvinyl alcohol blend films. The mechanical results showed that the surface photo cross-linking modification increased tensile strength and Young's modulus but decreased elongation at break of the TPS/ polyvinyl alcohol films.

Ray et al., (2009a) prepared starch/polyvinyl alcohol blends, and glycerol was added as a plasticizer. Physico-mechanical and morphological properties were determined. When a crosslinking agent like epichlorohydrin is used, it makes ether linkages with the available hydroxyl groups presented in starch and polyvinyl alcohol, which, depending on the type of intermolecular network structure formed, modifies the mechanical properties of the film.It was found that the presence of the cross-linking agent in the blend improves the mechanical properties, especially tensile strength and breaking energy.

Another study was made by Ray et al., (2009b) they prepared starch/ polyvinyl alcohol blends (glycerol was used as a plasticizer). The blends were characterized with dynamic mechanical analysis and TGA. It was found that starch/polyvinyl alcohol/glycerol (50/50/30) \%wt. presence of greater proportion of polyvinyl alcohol chains, which are more flexible than the starch molecules, inherent rigidity is less showing a lower storage modulus value.

In the study of Zhou et al., (2009) studied the effect of a complex plasticizer (a mixture of glycerol and urea) on the properties of starch/polyvinyl alcohol blends were examined. The results showed that the complex of glycerol and urea form more stable and strong hydrogen bonds with water and starch-polyvinyl alcohol molecules than the single plasticizer such as glycerol. Such blends with complex plasticizer had better mechanical properties.

The anaerobic degradability of TPS/polyvinyl alcohol blends were studied by Russo et al., (2009) the results showed that predominantly polyvinyl alcohol remained at the end of the digestion and that starch is almost entirely degraded. The polyvinyl alcohol content significantly impacted on the rate of starch solubilisation.

For the enzymatic degradation of TPS/PVOH blends, PVOH significantly impacts on the rate and extent of starch hydrolysis within the blend. This suggests that this may have been attributed to interactions between starch and polyvinyl alcohol that further prevented enzymatic attack on the remaining starch phases within the blend.

\section{Polypropylene}

Rosa and Pedroso (2005) blended TPS with recycled PP. The addition of TPS to recycled PP reduced the melt flow index of PP blends. Also it was found that the addition of $30 \%$ of TPS reduced drastically for PP, which suggests that TPS behaved as a nonreinforcing filler. A decrease of the mechanical properties of all formulations developed was observed, which can be justified by a phase separation between the 
polyolefins and TPS. SEM study confirmed the poor adhesion and interfacial interaction between PP and TPS in the prepared blends.

The mechanical properties showed that the stress at break of the blends increases slightly with increasing glycerol content while it decreases with increasing TPS content, which indicated the potential of tailoring the mechanical properties of the blend through appropriate glycerol content at a low content of TPS. Also it was found that Young's modulus of blends is higher than that of PP.

\section{Polystyrene}

Polystyrene (PS) is available in a range of grades which generally vary in impact strength from brittle to very tough. The nonpigmented grades have crystal clarity and overall their low cost coupled with ease of processing makes them used for such things as model aircraft kits, vending cups, yoghurt containers, light fittings, coils, relays, disposable syringes and casings for ballpoint pens.

With a higher ratio of TPS the addition of PS with glycerol as plasticizer increased thermal degradation of PS (Schlemmer et al., 2007). In a recycled PS blend with TPS, it was found that a lowering of the glass transition temperature occurs as the TPS content increases in the blends with widening of the peak until its complete disappearance, which reveals starch incorporation in the films and greater easiness of thermal degradation.

In another work, Schlemmer et al., (2007) studied the biodegradation of TPS/PS blends, starch was plasticized using glycerol and buriti oil as plasticizers. Thermal degradation stages related to TPS, which occur at lower temperatures did not appear in TGA curves after the test, indicating that the materials responsible for this degradation did not exist in blends anymore. The obtained results showed that buriti oil can be used as an environmentally friendly alternative to other materials, and has superior properties compared to glycerol, the most used plasticizer for starch.

\section{Polylactic acid blends}

Polylactic acid (PLA) is well-known aliphatic polyesters derived from corn and sugar beets, and it degrades to non-toxic compounds in landfill. Until the last decade, the main uses of PLA have been limited to biomedical and pharmaceutical applications such as implant devices, tissue scaffolds, and internal sutures, because of its high cost and low molecular weight. The new method of PLA synthesis (ring opening polymerization), which allows economical production of high molecular weight PLA polymer, has broadened its applications.

In a TPS/PLA blend, the lack of affinity between the TPS and PLA was a severe limitation and emphasized the need for some compatibilization strategy. This compatibilization strategy was applied by Li and Huneault (2011) using PLA grafted maleic anhydride (PLA-g-MA)/TPS blends and glycerol was used for starch plasticizing. It was found that PLA-g-MA/TPS blend is more ductile compared with TPS/PLA: elongation at break of modified blends was in the 100-200\% range compared to 5-20\% for non-modified blend and for the pure PLA. Wang et al., (2008) prepared PLA/TPS blends; maleic anhydride was used as a compatibilizer in presence of DCP. The mechanical tests of the prepared blends showed that the tensile strength of the compatibilized blends was higher than that of original blends. Wang et al., (2008) reported that use of both citric acid and formamide as a compatibilizer on the properties of TPS/PLA blends with glycerol as a plasticizer, the 
viscosity of the blend decrease with increasing citric acid and formamide, which enhances the dispersion between TPS and PLA in the blend. Also the additives improve the thermal stability of the blend.

In an experiment on effect of different plasticizers (glycerol, formamide, and water) in the properties of PLA/TPS blend, it was found that formamide is the most suitable plasticizer for starch, although water was effective plasticizer whereas glycerol was very poor plasticizer (Wang et al., 2008). Out of glycerol, sorbitol and mixture of glycerol/sorbitol plasticizer for TPS/PLA blends, the glycerol/sorbitol ratio has an important effect on the blend properties. Sorbitol plasticized blends have higher tensile strength and modulus compared with glycerol plasticized blends (Li and. Huneault, 2011).

In conclusions, starch is renewable from carbon dioxide, water and sunshine. It is biodegradable, cheap and to be physical or chemical modified easily. Starch films have been obtained by casting or by thermal processing when thermoplastic starch was used. A great number of components have been added to the matrix, and process variables changed, in order to improve film properties. When the conditions are optimized, the obtained films are transparent, odorless, tasteless, and colorless, with good mechanical, barrier, and optical properties. Nevertheless, retrogradation phenomenon and the highly hydrophilic nature of starch films limit their usefulness. The incorporation of some additives, such as lipids, other hydrocolloids, or reinforcement agents, can solve these problems to quite an extent, giving rise to more stable materials with improved properties. Industrial progress in packaging technology in future appears to be moving forwards newer breed of biomaterials. To that end, there is a need to perpetuate the culture of environmental stewardship and sustainability that has grown stronger in recent years. Although some of the starch-based materials and other biopolymers may not currently be cost-competitive with petroleum plastics, this may change as petroleum prices continue to increase. Improved the properties of starch-based plastics by blending starch with other polymers, using starch in composite materials, and using starch as a biodegradable feedstock to make other biopolymers have been successful in developing viable replacements for petroleum based plastics. The prospects for starch in the packaging sector continue to become brighter as the market for sustainable plastics drives further innovation and development.

\section{References}

Alay, S. C. A. and Meireles, M. A. A. 2015. Physicochemical properties, modifications and applications of starches from different botanical sources. Food Science Technology. 35(2): 215-236.

Alves, D. V., Mali, S., Beleia, A. and Grossmann, E. M. 2007. Effect of glycerol and amylose enrichment on cassava starch film properties. Journal of Food Engineering. 78(3): 941-946.

Arevalo-Nino, K., Sandoval, C. F., Galan, L. J., Imam, S. H., Gordon, S. H. and Greene, R. V. 1996. Starch-based extruded plastic films and evaluation of their biodegradable properties. Biodegradation. 7: 231.

Arvanitoyannis, I. 1999. Totally and partially biodegradable polymer blends based on natural and synthetic macromolecules: preparation, physical properties, and potential as food packaging materials. Journal of Macromol. Science, Polymer Review. 39(2):205-271.

Arvanitoyannis, I., Nakayama, A. and Aiba, S. 1998. Edible films made from 
hydroxypropyl starch and gelatin and plasticized by polyols and water Carbohydrate. Polymer. 36(2-3):105119.

Averous, L. and Halley, P. J. 2009. Biofuels. Bioproducts and Biorefining. 3: 329343.

Averous, L., Moro, P., Dole and Fringant, C. 2000. Polymer. 41: 4157-4167.

Baks, T., Bruins, M. E., Janssen, A. E. M. and Boom, R. M. 2008. Effect of pressure and temperature on the gelatinization of starch at various starch concentrations. Biomacromolecules. 9(1):296-304.

Banker, G. S. 1966. Film coating theory and practice. Pharmaceutical Sciences. 55(1): 81-89.

Be Miller, J. and Whistler, R. 2009. Starch: Chemistry and Technology. 3rd ed. Elsevier Inc.

Be Miller, J. N. 2011. Pasting, paste, and gel properties of starch-hydrocolloid combinations. Carbohydrate Polymers. 86(2):386-423.

Belgacem, M. N. and Gandini, A. 2008. Monomers, Polymers and Composites from Renewable Resources.

Billmeyer, F. W. J. 1984. Textbook of polymer science. $3^{\text {rd }}$ Ed. John Wiley and Sons. Inc.

Bourtoom, T. 2008. Plasticizer effect on the properties of biodegradable blend film from rice starch-chitosan. Journal of Science and Technology. 30(1):149165.

Bourtoom, T. and Chinnan, M. S. 2008a. Plasticizer effect on the properties of biodegradable blend film from rice starch-chitosan. LebensmittelWissenschaft Und-Technologie. 41(9):1633-1641.

Bourtoom, T. and Chinnan, M. S. 2009. Improvement of water barrier property of rice starch chitosan composite film incorporated with lipids. Food Science and Technology International. 15(2):
149-158.

Brown, W. H. and Poon, T. 2005. Introduction to Organic Chemistry (3rd ed.). Wiley, London. 324 -341.

Campos, C. A., Gerschenson, L. N. and Flores, S. K. 2011. Development of edible films and coatings with antimicrobial activity. Food and Bioprocess Technology. 4(6):49-875.

Casto-Rosas, J., Crus-Galvez, A. M., GomezAldapa, C. A., Falfan-Cortes, R. N., Guzman-Ortiz, F. A. and RodriguezMartin, M. L. 2016. Biopolymer films and the effects of added lipids, nanoparticles and antimicrobials on their mechanical and barrier properties: a review. International Journal of Food Science and Technology. 51:1967-1978.

Chang, Y. P., Karim, A. and Seow, C. C.2006. Interactive plasticizingantiplasticizing effects of water and glycerol on the tensile properties of tapioca starch films. Food Hydrocolloids. 20:1-8.

Chauvan, G.S. 2003. Effect of extrusion cooking on $\mathrm{X}$-ray diffraction, characteristics of rice and rice legume blends. International Journal of Food Properties. 6(1).

Chen, Jen-Fang. 1990. Effect of amylose and amylopectin on the functional properties of starch. Retrospective Theses and Dissertations. 16727.

Chen, Jen-Fang. 1990. Effect of amylose and amylopectin on the functional properties of starch. Retrospective Theses and Dissertations. 16727.

Chinma, C. E., Ariahu, C. C., Alakali, J. S. 2015. Effect of temperature and relative humidity on the water vapour permeability and mechanical properties of cassava starch and soy protein concentrate based edible films. Journal of. Food Science Technology. 52(4):2380-2386.

Cinelli, P., Chiellini, E., Gordon, L. S. H. and 
Chiellini, L. E. 2005. Characterization of biodegradable composite films prepared from blends of poly(vinyl alcohol), cornstarch, wheat flour. Carbohydrate Polymers. 60:111-116.

Colussi, R., Pinto, V. Z., Halal, S. L. M., Biduski, B., Prietto, L., Castilhos, D. D., Zavareze, E. R. and Dias, A. R. G. 2017. Acetylated rice starches films with different levels of amylose: Mechanical, water vapor barrier, thermal, and biodegradability properties. Food Chemistry. 221: 16141620.

Conde-Petit, B., Nuessli, J., Arrigoni, E., Escher, F. and Amadòo R. 2001. Perspectives of starch in food science. Chimia. 55(3):201-205.

Da Roz, A. L., Carvalho, A. J. F., Gandini, A. and Curvelo, A. A. S. 2006. The effect of plasticizers on thermoplastic starch compositions obtained by melt processing. Carbohydrate Polymers. 63: 417-424.

Dai, H., Chang, P. R., Geng, F., Yu, J. and Ma, X. 2010. Type and content of plasticizer affected the properties of corn starch films. Carbohydrate Polymers. 79(2): 306-311.

Dai, H., Chang, P. R., Yu, J. and Ma, X. F. 2008. N,N-Bis(2-hydroxyethyl) formamide as a New Plasticizer for Thermoplastic Starch. Starch-Starke. 60:676-684.

Domingos, F., De Sousa, Holanda-Araujo, M. L. and Rodrigues De Souza, J. R. 2017. Physicochemical properties of edible seed hemicelluloses. Open Access Libr.J. 4.

Fakhouri, F. M., Fontes, L. C. B., InnocentiniMei, L. H. and Collares-Queiroz, F. P. 2009. Effect of fatty acid addition on the properties of biopolymer films based on lipophilic maize starch and gelatin. StarchStarke. 61:528-536.

Fama, L., Flores, S. K., Gerschenson, L. and
Goyanes, S. 2006. Physical characterization of cassava starch biofilms with special reference to dynamic mechanical properties at low temperatures. Carbohydrate Polymers. 66: 8-15.

Fama, L., Goyanes, S. and Gerschenson, L. 2007. Influence of storage time at room temperature on the physicochemical properties of cassava starch films. Carbohydrate Polymers. 70:265-273.

Fang, J., Fowler, P., Sayers, C. and Williams, P. 2004. The chemical modification of a range of starches under aqueous reaction conditions, Carbohydr. Polym. 55(3):283-289.

Fishman, M. L. and Coffin, D. R., Two stage extrusion of plasticized pectin/poly(vinyl alcohol) blends. Carbohydrate Polymers. (65):421-429.

Forssell, P. M., Hulleman, S. H. D., Millarinen, P. J., Moates, G. K. and Parker, R. 1999. Ageing of rubbery thermoplastic barley and oat starches. Carbohydrates Polymers. 39(1): 43-51.

Forssell, P. M., Mikkila, J. M., Moates, G. K., Parker, R. 1997. Phase and glass transition behavior of concentrated barley starch-glycerol-water mixtures, a model for thermoplastic starch. Carbohydrate Polymers. 34(4):275282.

Fredrikssona, H., Silveriob, J., Andemon, R., Eliassonb, A. C. and Aman, P. 1998. The influence of amylose and amylopectin characteristics on gelatinization and retrogradation properties of different starches. Carbohydrate Polymers. 35:119-134.

French, D. 1984. Organization of starch granules. In R. L. Whistler, J. N. Bemiller, and E. F. Paschall (Eds.), Starch: chemistry and technology. (2nd ed.). Orlando: Academic Press Inc.

Galus, S. and Kadzinska, J. 2016. Whey protein edible films modified with 
almond walnut oils. Food Hydrocolloids. 52:78-86.

Gandini, A., Lacerda, T., Carvalho, A. J. F. and Trovatti, E. 2016. Progress of polymers from renewable resources: furans, vegetable oils, and polysaccharides. Chem. Rev. 116(3):163-166.

Gao, H., Cai, J., Han, W., Huai, H., Chen, Y. and Wei, C. 2014. Comparison of starches isolated from three different trapa species. Food Hydrocolloids. 37:174-181.

Garcia, M. A., Martino, M. N. and Zaritzky, N. E. 2000a. Lipid addition to improve barrier properties of edible starch-based films and coatings. Journal of Food Science. 65(6): 941-947.

Gaudin, S., Lourdin, D; Le Botlan, D., Ilari, J. L. and Colonna, P. 1998. Plasticisation and Mobility in Starch-Sorbitol Films. Cereal Science. 29:273-284.

Gioia, L. and Guilbert, S. 1999. J. Agric. Food Chem. 47: 1254-1261.

Godbillot, L., Dole, P., Joly, C., Roge, B. and Mathlouthi, M. 2006. Analysis of water binding in starch plasticized films. Food Chemistry. 96: 380-386.

Greener, J. K. and Fennema, O. 1989. Barrier properties and surface characteristics of edible bilayer films. Food Science. 54(6): 1393-1399.

Griffin, G. 1976. Degradation of polyethylene in compost burial. Polymer Science Sym. 57:281.

Griffin, G. J. L. 1994. Starch polymer blends. Polymer. Degradation and Stability. 45: 241-247.

Gudmundsson, M. 1994. Retrogradation of starch and the role of its components. Thermochimica Acta. 246:329-341.

Gudmundsson, M. and Eliasson, A. C. 1990. Retrogradation of amylopectin and the effects of amylose and added surfactants/emulsifiers. Carbohydrate Polymers. 13:295-315.
Haggenmaier, R. D. and Shaw, P. E. 1990. Moisture permeability of edible films made with fatty acid and (hydrocypropyl) methylcellulose. Agricultural and Food Chemistry. 38(9): 1799-1803.

Hernandez, R. J. 1994. Effect of water vapour on the transport properties of oxygen through polyamide packaging materials. Food Engineering. 22(1-4): 495-507.

Hizukuri, S., Takeda, Y. and Yasuda, M. 1981. Multi-branched nature of amylose and the action of debranching enzymes. Carbohydr. Res. 94:205-213.

Hoover, R. 2000. Acid-treated starches. Food Reviews International. 16(3):369-392.

Hoover, R. 2001. Composition, molecular structure, and physicochemical properties of tuber and root starches: a review. Carbohydrate Polymers. 45:253-267.

Huang, M., Yu, J. and Ma, X. 2006. Carbohydr. Polym. 63: 393-399.

Jangehud, A. and Chinnan, M. S. 1999. Properties of peanut protein film: sorption isotherm and plasticizer effect. Food Science and Technology. 32:8994.

Jayasekara, R., Harding, I., Bowater, I., Lonergan, G. 2005. Biodegradability of Selected Range of Polymers and Polymer Blends and Standard Methods for Assessment of Biodegradation. Journal of Polymer Environ. 13:231.

Jiang, T., Duan, Q., Zhu, J., Liu, H. and Yu, L. 2020. Starch-based biodegradable materials: Challenge and opportunities. Advanced Industrial and Engineering Polymer Research. 3:8-18.

Jimenez, A., Fabra, M. J., Talens, P. and Chiralt, A. 2012. Effect of recrystallization on tensile, optical and water vapour barrier properties of corn starch films containing fatty acids. Food Hydrocolloids. 26(1):302-310.

Karim, A. A., Norziah, M. H. and Seow, C. C. 
2000. Methods for the study of starch retrogradation. Food Chemistry. 71:936.

Kaya, S.and Maskan, A. 2003. Water vapor permeability of pestil made from boiled grape juice with starch. Journal of Food Eng. 57: 295-299.

Kechichian, V., Ditchfield, C., Veiga-Santos, P. and Tadini, C. C. 2010. Natural antimicrobial ingredients incorporated in biodegradable films based on cassava starch. Food Science and Technology. 43:1088-1094.

Kester, J. J. and Fennema, O. R. 1986. Edible films and coatings: A review. Food Technology. 40(12): 1365-2621.

Koganti, N., Mitchell, J. R., Ibbett, R.N. and Foster, T. J. 2011. Solvent effects on starch dissolution and gelatinization. Biomacromolecules. 12 (8):288-289.

Kowalczyk, D. and Baraniak, B. 2014. Effect of candelilla wax on functional properties of biopolymer emulsion films. A comparative study. Food Hydrocolloids. 41:195-209.

Li, H. and. Huneault, M. A. 2011. J. Appl. Polym. Sci. 119:2439-2448.

Liu, H., Xie, F., Yu, L., Chen, L., and Li, L. 2009. Thermal processing of starchbased polymers. Prog. Polym. Sci. 34(12):1348-1368.

Liu, Q. and Thompson, D. B. 1998 Effect of moisture content and different gelatinization heating temperatures on retrogradation of waxy-type maize starches. Carbohydrate Research. 314:221-235.

Liu, Q. and Thompson, D. B. 1998. Retrogradation of maize starches after different gelatinization heat treatments. Cereal Chemistry. 75(6): 868-874.

Loewus, F. A. and Briggs, D. R. 1957. A potentiometric study of the change in iodine binding capacity of amylose while retrograding in dilute solution. Journal of the American Chemical
Society. 79:1494-1497.

Lourdin, D., Colonna, P. and Ring, S. G. 2003. Volumetric behaviour of maltose / water, maltose/ glycerol and starch / sorbitol / water systems mixtures in relation to structural relaxation. Carbohydrate Research. 338:28832887.

Ma, X. and Yu, J. 2004. Carbohydr. Polym. 57: 197-203.

Ma, X. F. Y., Yu, J. G. and Wan, J. J. 2006. Urea and ethanolamine as a mixed plasticizer for thermoplastic starch. Carbohydrate Polymers. 64:267-273.

Mali, M. V. E., Grossmann, M. A., Garcia, M. N., Martino and Zaritzky, N. E. 2002. Microstrucural characterization of yam starch films. Carbohydrate Polymers. 50: 379-386.

Mali, S., Grossmann, M. V. E., García, M. A., Martino, M. N. and Zaritsky, N. E. 2006. Effects of controlled storage on thermal, mechanical and barrier properties of plasticized films from different starch sources. Journal of Food Engineering. 75:453-460.

Mali, S., Sakanaka, L. S., Yamashita, F., and Grossmann, M. V. E. 2005. Water sorption and mechanical properties of cassava starch films and their relation to plasticizing effect. Carbohydrate Polymers. 60(3):283-289.

Mao, L. and Imam, S. 2000. Extruded cornstarch-glycerol-polyvinyl alcohol blends: mechanical properties, morphology and biodegradability. Polymer Environment. 8:205-211.

Masclaux, C., Gouanve, F. and Espuche, E. 2010. Experimental and modelling studies of transport in starch nanocomposite films as affected by relative humidity. Membrane Science. 363(1-2): 415-421.

Mekonnen, T., Mussone, P., Khalil, H. 2013. Progress in bio-based plastics and plasticizing modifications. Journal of 
Materials Chemistry A. 1(43): 13379 13398.

Miles, M. J., Morris, V. J. and Ring, S. G. 1985. Gelation of Amylose. Carbohydrate research. 135:257296.

Ming, L., Penf, L., Wei, Z., Long, Y., Fengwei, X., Huanyin, P., Hongshen, L. and Ling, C. 2011. Extrusion processing and characterization of edible starch films with different amylose contents. Food Engineering. 106(1): 95-101

Mohammadi Nafchi, M. A., Moradpour, M., Saeidi and Alias, A. K. 2013. Starch-Starke. 65: 61-72.

Mooney, B. P. 2009. Production of plantbased biodegradable plastics. Journal of chemistry. 418 (2):219-232.

Muscat, D., Tobin, M. J., Guo, Q. and Adhikari, B. 2014. Understanding the distribution of natural wax in starchwax films using synchroton-based FTIR (S-FTIR). Carbohydrate Polymers. 102:125-135.

Myllarinen, P., Buleon, A., Lahtinen, R. and Forssell, P. 2002. The crystallinity of amylose and amylopectin films. Carbohydrate Polymers. 48:41-48.

Oses, J., Fabregat-Vazquez. M., PedrozaIslas, R., Tomas, S. A., Cruz-Orea, A. and Mate, J. I. 2009. Development and characterization of composite edible films based on whey protein isolate and mesquite gum. Journal of Food Eng. 92:56-62

Othman, S. H., Edwal, S. A. M., Risyon, N. P., Basha, R. K., and Talib, R. A. 2017. Water sorption and water permeability properties of edible film made from potato peel waste. Food Science and Technology. 37(1):63-70.

Othman, S. H., Kechik, N. R. A., Shapi'I, R. A., Talib, R. A., Tawakkal, I. S. M. A. 2019. Water sorption and mechanical properties of starch/chitosan nanoparticle films. Journal of
Nanomaterials.

Pareta, R. and Edirisinghe, M. J. 2006. A novel method for the preparation of starch films and coatings. Carbohydrate Polymer. 63: 425-431.

Park, J. S., Yang, J. H., Kim, D. H. and Lee, D. H. 2004. Degradability of expanded starch/PVA blends prepared using calcium carbonate as the expanding inhibitor. Journal of Applied Polymer Science. 93: 911-919.

Parra, D. F., Tadini, C. C., Ponce, P. and Lugao, A. B. 2004. Mechanical properties and water vapor transmission in some blends of cassava starch edible films. Carbohydrate Polymers. 58:475481.

Peroval, C., Debeaufort, F. and Voilley, A. 2002. Effects of lipids type on water vapor permeability, film structure, and other physical characteristics. Journal of Agricultural and Food Chemistry. 50:3977-3983.

Peterson, M. and Stading, M. 2005. Water vapour permeability and mechanical properties of mixed starchmonoglyceride films and effect of film forming conditions. Food Hydrocolloids. 19: 123-132.

Ray, S., Yamada, K., Okamoto, M. and Ueda, K. 2009a. Prepared starch/polyvinyl alcohol blends, and glycerol was added as a plasticizer. Journal of nanoscience nanotrchnology. 3: 503-510.

Ray, S., Yamada, K., Okamoto, M. and Ueda, K. 2009b. Prepared starch/ polyvinyl alcohol blends. Polymer. 44: 857-866.

Rhim, W. J. and Shellhammer, H. T. 2005. Lipid based edible films and coating. Innovations in food packaging.

Rindlav-Westling, A., Stading, M., Hermansson, A. M. and Gatenholm, P. 1998. Structure, mechanical and barrier properties of amylose and amylopectin films. Carbohydrate. Polymer. 36 (2-3): 217-224. 
Ring, S.G., Colonna, P., Anson, K. J., Kalichevsky, M. T., Miles, M. J., Morris, V. J. and Orford, P. D. 1987. The gelation and crystallisation of amylopectin. Carbohydrate research. 162:277-293.

Rocca-Smith, J. R., Marcuzzo, E. and Karbowiak, T. 2016. Effect of lipid incorporation on functional properties of wheat gluten based edible films. Journal of Cereal Science. $\quad 69: 275$ 282.

Rodriguez-Gonzalez, F. J., Ramsay, B. A. and Favis, B. D. 2004. Rheological and thermal properties of thermoplastic starch with high glycerol content. Carbohydrate Polymers. 58:139-147.

Rosa, D. S. and Pedroso, A. G. 2005. Blended TPS with recycled PP. Carbohydrate Polymer. 59:1-9.

Russo, M. A. L., Sullivan, C., Rousefell, B., Halley, P. J. and Truss, R. 2009. The anaerobic degradability of thermoplastic starch/polyvinyl alcohol blends: potential biodegradable food packaging materials. Bioresources and Technology. 100:1705-1710.

Sasaki, M., Fang, Z., Fukushima, Y., Adschiri, T., and Arai, K. 2000. Dissolution and hydrolysis of cellulose in subcritical and supercritical water. Industrial and Engineering Chemistry Research. 39(8):2883-2890.

Schlemmer, D., De Oliveira, E. R. and Maria Jose Araujo Sales. 2007. biodegradation of TPS/PS blends, starch was plasticized using glycerol and buriti oil as plasticizers. Journal of Thermal Analysis and Calorimetry. 87(3):635638

Schwach, E. and Averous, L. 2004. Starchbased biodegradable blends: Morphology and interface properties. Polymer International. 53: 2115-2124.

Schwartz, D. and Whistler, R. L. 2009.
History and future of starch. In $\mathbf{J}$. Bemiller and R. Whistler (Eds.), Starch chemistry and technology. New York, New York: Academic Press.

Setiawan, H. S., Widjaja, V., Rakphongphairoj and Jane, J. 2010. J. Agric. Food Chem. 58:12260-12267.

Shujun, W., Jiugao, Y., Jinglin, Y. 2006. Preparation and characterization of compatible and degradable thermoplastic starch/polyethylene film. Journal of Polym Environm. 14:1.

Singh, N., Singh, J., Kaur, L., Sodhi, N. S. and Gill, B. S. 2003. Morphological, thermal and rheological properties of starches from different botanical sources. Food Chemistry. 81(2): 219231.

Sjoqvist, M. and Gatenholm, P. 2007. Journal of Polymers and the Environment. 15: 43-50.

Smith, J. K. 2001. Technology and Culture. 34-55.

Smith, J. K. 2001. Technology and Culture. 34-55.

Sreedhar, B., Malladi, S., Chattopadhyay, D., Syamala Rathnam, P. A. and Mohan Rao, D. V. 2006. Starch/polyvinyl alcohol blends crosslinked with epichlorhydrin using different plasticizers such as PEG and glycerol. Journal of Applied Polymer Science. 96(4):1313-1322.

Srinivasa, P. C., Ramesh, M. N. and Tharanathan, R. N. 2007. Effect of plasticizers and fatty acids on mechanical and permeability characteristics of chitosan films. Food Hydrocolloids. 21(7): 1113-1122.

Stading, M., Rindlav-Westling, A. and Gatenholm P. 2001. Humidity-induced Structural Transitions in Amylose and Amylopectin Films. Carbohydrate Polymers. 45(3): 209-217.

Stepto, R. F. T. 2006. Understanding the processing of thermoplastic starch. 
Macromolecular Symposia. 571-577.

Suppakul P., Chalernsook, B., Ratisuthawat, B., Prapasitthi, S., and Munchukangwan, N. 2013. Empirical modeling of moisture sorption characteristics and mechanical and barrier properties of cassava flour film and their relation to plasticizingantiplasticizing effects. Food Science and Technology. 50(1):290-297.

Taguet, A., Huneault, M. A., Favis, B. D. $2009 . \quad$ Interface/morphology relationships in polymer blends with thermoplastic starch. Polymer. 50:57335743.

Takeda, C., Takeda, Y. and Hizukuri, S. 1989. Structure of amylomaize amylose. Cereal Chern. 66(1):22-25.

Talja, R. A. 2007. Preparation and characterization of potato starch films plasticized with polyols, in Faculty of Agriculture and Forestry., University of Helsinki: Viikki, Helsinki. 57.

Talja, R. A., Helen, H., Roos, Y. H., and Jouppila, K. 2007. Effect of various polyols and polyolcontents on physical and mechanical properties of potato starch-based films. Carbohydrate Polymers. 67(3): 288-295.

Talja, R. A., Helen, H., Roos, Y. H. and Jouppila, K. 2008. Effect of type and content of binary polyol mixture on physical and mechanical properties of starch-based edible films. Carbohydrate Polymers. 71: 269-276.

Tan, H. Z., Gu, W. Y., Zhou, J. P., Wu, W. G. and Xie, Y. L. 2006. Comparative study on the starch noodle structure of sweet potato and mung bean. Journal of Food Science. $\quad 71(8): 447-455$.

Teramoto, N., Motoyama, T., Yosomiya, R. and Shibata, M. 2003. Synthesis, thermal properties, and biodegradability of propyl-etherified starch. Journal of European Polymer. 39: 255-261.

Tongdeesoontorn, W., Mauer, L. J.,
Wongruong, S., Sriburi, P., Rachtanapun, P. 2011. Effect of carboxymethyl cellulose concentration on physical properties of biodegradable casaba starch-based films. Chemistry Cetnral Journal. 5(6):1-8.

Tyagi, V. and Bhattacharya, B. 2019. Role of plasticizers in bioplastic. Food Process Technol. 7(4):128-130.

Tyson, R. H. and Ap Rees, T. 1988. Starch synthesis by isolated amyloplasts from wheat endosperm. Planta. 175:33-38.

Van Soest, J. J. G. and Essers, P. 1997. Influence of Amylose-Amylopectin Ratio on Properties of Extruded Starch Plastic Sheets. Macromolecular Science. 34(9):1665-1689.

Van Soest, J. J. G., Hulleman, S. H. D., Wit, D. and Vliegenthart, J. F. G. 1996. Crystallinity in starch bioplastics. Ind Crps Prdts. 5(1):11-22

Veiga-Santos, P., Oliveira, L. M., Cereda, M. P., Scamparini, A. R. P. 2007. Sucrose and inverted sugar as plasticizer. Effect on cassava starch-gelatin film mechanical properties, hydrophilicity and water activity. Food Chemistry. 103.

Veiga-Santos, P., Suzuki, C. K., Nery, K. F., Cereda, M. P. and Scamparini, A. R. P. 2008. Evaluation of optical microscopy efficacy in evaluating cassava starch biofilms microstructure. Food Science and Technology. 41:1506-1513.

Vermeylen, R., Derycke, V., Delcour, J. A., Goderis, B., Reynaers H. and Koch, M. H. J. 2006. Gelatinization of starch in excess water: Beyond the melting of lamellar crystallites. Biomacromolecules. 7:2624-2630.

Vieira M. G. A., Silva, M. A. and Santos, L. O. 2011. Natural-based plasticizers and biopolymer films: A review. European Polymer Journal. 47(3):254-263.

Wang, N. J., Yu, P. R., Chang and Ma, X. 2008. Carbohydr. Polym.71: 109-118. 
Wang, S., Li, C., Copeland, L. and Niu, Q. 2015. Starch retrogradation: a comprehensive review. Comprehensive Reviews in Food Science and Food Safety. 14 (5):56-58.

Westling, R. A., Stading, M. and Gatenholm, P. 2002. Crystallinity and morphology in films of starch, amylase and amylopectin blends. Bio Macromolecules. 3(1): 84-91

Whistler, R. L. 1984. History and future expectation of starch use. In R. L. Whistler, J. N. Bemiller, and E. F. Paschall (Eds.), Starch: Chemistry and technology. (2nd ed.). New York: Academic Press.

Whistler, R. L., Bemiller, J. N. and Paschall, E. F. 1984. Starch: Chemistry and technology. NewYork: Academic Press.

Xu, L., Jiang, X., Zhaol, Y. and Liru, X. 2017. Preparation of starch-based biodegradable film and the application in agriculture. Journal of Agricultural Science. 9(3): 68-71.

Yang, J. H., Yu, J. G. and Ma, X. F. 2006. A Novel Plasticizer for the Preparation of Thermoplastic Starch. Chinese Chemical Letters. 17(1):133-136.

Yang, J., Yu, J. and Ma, X. 2006a. Carbohydr. Polym. 66: 110-116.

Yang, L. and Paulson, A. T. 2000. Effects of lipids on mechanical and moisture barrier properties of edible gellan film. Food Research International. 33(7):571-578.
Yoon, S. D., Chough, S. H. and Park, H. R. 2006. Effects of Additives with Different Functional Groups on the Physical Properties of Starch/PVA Blend Film. Journal of Applied Polymer Science. 100(5):3733-3740.

Yu, L., Christie, G. 2005. Microstructure and mechanical properties of orientated thermoplastic starches. Journal of Material Science. 40(1):111-16.

Yu, L., Dean, K., Li, L. 2006. Polymer blends and composites from renewable resources. Prog. Polymer Science. 31(6):576-602.

Yuan, R. C., Thompson, D. B. and Boyer, C. D. 1993. Fine structure of amylopectin in relation to gelatinization and retrogradation behavior of maize starches from three wx-containing genotypes in two inbred lines. Cereal Chemistry. 70:81.

Zhang, C. Y., Rempel and Liu, Q. 2014.Crit. Rev. Food Sci. Nutr. 54:1353-1370.

Zhang, J. F. and Shun, X. Z. 2004. Mechanical properties of PLA/starch composites compatibilized by maleic anhydride. Biomacromolecules. 5:14461451.

Zheng, P. R., Chang, J., Yu and Ma, X. 2009. Carbohydr. Polym. 2009.78: 296-301.

Zhou, J., Ma, Y., Ren, L. and Tong, J. 2009. Prepared and characterized of surface crosslinked TPS/polyvinyl alcohol blend films. Carbohydrate Polymers. 76(4):632-638.

\section{How to cite this article:}

Neha J. Hirpara and Dabhi, M. N. 2021. A Review on Effect of Amylose/Amylopectin, Lipid and Relative Humidity on Starch Based Biodegradable Films. Int.J.Curr.Microbiol.App.Sci. 10(04): 500-531. doi: https://doi.org/10.20546/ijcmas.2021.1004.051 